\title{
Spinnengemeinschaften mitteleuropäischer Kulturbiotope
}

\section{Ralph PLATEN}

\begin{abstract}
Spider communities of arable land in central Europe. This paper contains an analysis of the species composition and dominance structure of the spider fauna of 13 different arable land sites in Berlin. Investigations were performed by pitfall trapping from April to December 1981. Species composition was extremely uniform despite different microclimatic conditions (soil humidity, light and temperature) and crop types. Only slight differences were found in the composition of abundant species. A multivariate analysis of species, together with microclimatic data, revealed that the measured abiotic factors do not explain the distribution of the species. Nearly all dominant spiders belong to eurytopic species of open habitat types. Spider community descriptions were enhanced by evaluation of references concerning the spider fauna of arable land in central Europe. The composition of abundant species was nearly the same throughout the area. This applies to all different arable sites and furthermore to sites which are related to them ecologically (abandoned grassland, field margins, meadows and pastures). A way in which spiders may colonize arable land is discussed critically.
\end{abstract}

Key words: Spiders, spider communities, arable land, zoogeography, colonization strategies

\section{EINFÜHRUNG UND PROBLEMSTELLUNG}

Bei Untersuchungen von Arthropodenzönosen in Kulturbiotopen standen in den letzten Jahren bei Biologen und Landwirten folgende Problemstellungen im Vordergrund:

- die Bedeutung der Spinnen als Schädlingsprädatoren (KRAUSE 1987, LYS \& NENTWIG 1992, NYFFELER 1982)

- Zusammensetzung und Besiedlungsdynamik, Einfluß der mechanischen Bearbeitung auf die Arthropodenfauna (BÜCHS 1993, HEYDEMANN 1953, KAJAK 1980, KLEINHENZ \& BÜCHS 1993, LUCZAK 1975)

- Rückgang der Besiedlungsdichte bzw. Ausfall ganzer Artengruppen durch den Einsatz von Bioziden bzw. durch ihren Einsatz hervorgerufene Strukturverarmung sowie durch Beseitigung von Ackerrandstreifen und Hecken (BASEDOW 1973, BASEDOW et al. 1976, BASEDOW \& MIELKE 1977, BASEDOW \& RZEHAK 1988, BLICK 1988, KRAUSE 1987, TURLEY 1985, ZWÖLFER 1981) 
Mit der vorliegenden Untersuchung soll herausgearbeitet werden, daß in mitteleuropäischen Kulturflächen je nach aktueller Anbaufrucht, Fruchtfolge und Bodentyp charakteristische Spinnenzönosen leben. Feldpfuhle, Ackerrandstreifen, Hecken und Ackerbrachen werden in die Analyse mit einbezogen, Wiesen und Weiden, d.h. Flächen, deren Fruchtanbau zur direkten oder indirekten Ernährung von Vieh dienen, bleiben dagegen weitgehend unberücksichtigt. Da das Kulturgrünland von der Bodenfeuchte (Naßwiesen bis sehr trockene Brachen), der anstehenden Vegetation (Kleinseggenriede bis Borstgrasrasen) und der Nutzungsart (Streuwiesen, zwei- bis mehrschürige Wirtschaftswiesen, extensiv bis intensiv gedüngte und beweidete Wiesen) sehr große standörtliche Unterschiede aufweist, würde eine vollständige Analyse der auch in diesen Biotoptypen erhobenen Daten den Rahmen dieser Arbeit sprengen. Schließlich soll diskutiert werden, ob es für Äcker typische Spinnenzönosen gibt, in welchen naturnahen Lebensräumen ihre Ursprünge zu suchen sind und auf welche Weise die Besiedlung erfolgt.

Als eine der Grundlagen für die Datenauswertung dienen eigene Untersuchungen unterschiedlicher Kulturflächen, die im Gebiet von West-Berlin im Jahre 1981 durchgeführt wurden. Weitere Ergebnisse, die in späteren Jahren im Rahmen von Diplom- bzw. Staatsexamensarbeiten in Berlin erarbeitet wurden, sind ebenfalls in die Analyse mit einbezogen worden.

Eine weitere Datengrundlage stellt die Auswertung der mir bekannten Literatur über Spinnenzönosen von Kulturstandorten Mitteleuropas dar, sofern sie auswertbare Daten enthalten. Es wurden folgende Arbeiten, differenziert nach Anbaufrucht, berücksichtigt (Mehrfachnennungen aufgrund der Untersuchung unterschiedlicher Feldfrüchte durch ein und denselben Autor können auftreten):

Halmfrucht:

ASHIKBAYEV (1973), BASEDOW (1973), BEYER (1981), BRUHN (1990), de CLERCQ (1979), COTTENIE \& de CLERCQ (1977), HEYDEMANN (1953), HUHTA \& RAATIKAINEN (1974), INGRISCH etal. (1989), KEGEL (1991), KRAUSE (1987),LUCZAK(1975), NYFFELER\& BENZ(1981), NYFFELER(1982), RAATIKAINEN\&HUHTA(1968), SZODRA(1983), THALER \& STEINER (1975), THALER etal. (1977), TISCHLER (1958), VICKERMAN \& SUNDERLAND (1975)

\section{Hackfrucht:}

ASSMUTH et al. (1986), BEYER (1981), CZAJKA \& KANIA (1976), HEYDEMANN (1953), INGRISCH et al. (1989), JANUSCH (1988), KLEINHENZ \& BÜCHS (1993), LUCZAK (1975), SZODRA (1983)

Mais:

KRAUSE (1987), LUCZAK (1975) 


\section{Obst:}

$\operatorname{BEYER}(1979)$

Luzerne, Klee:

BALOGH \& LOSKA (1956), BEYER (1981), JANUSCH (1988), LUCZAK (1975)

Wiesen:

BEYER (1978, 1981), BREYMEYER (1978), RABELER (1952), RUZICKA (1987), THALER et al. (1977)

Weiden:

KRAUSE (1987)

Feldgehölze, Ackerrandstreifen:

BLICK (1988), v. BROEN (1985), LUCZAK (1975), NÄHRIG (1987), SZODRA (1983), TISCHLER(1958)

\section{GEOMORPHOLOGIE UND KLIMA DES UNTERSUCHUNGSGEBIETES}

Das Gebiet von West-Berlin (Koordinaten $52^{\circ} 31^{\prime}$ nördl. Breite, $13^{\circ} 24^{\prime}$ östl. Länge) umfaßte eine Fläche von $480 \mathrm{~km}^{2}$. Das Relief ist, wie im übrigen norddeutschen Tiefland, durch die Gestaltungsdynamik des Weichselglazials geprägt worden.

Die Geomorphologie des Westberliner Raumes ist durch Hochflächen (Barnim im Norden, Nauener Platte im Westen und Teltow im Süden) und die sie durchschneidenden Abflußtäler (Warschau-Berliner Urstromtal in Ost-West-Richtung, Abflußrinne der Havel in Nord-Süd-Richtung) gekennzeichnet. Während die Hochflächen aus +/- mächtigen Geschiebemergelschichten bestehen, finden sich in den Tälern vor allem Sande (SUKOPP 1990). Landwirtschaftliche Nutzflächen sind daher vor allem im Norden Berlins (Lübars, Heiligensee, Spandau), im Westen (Gatow, Kladow) sowie im Süden der Stadt (Marienfelde, Rudow) vorhanden. Der Anteil der landwirtschaftlich genutzten Flächen betrug zur Untersuchungszeit 2,2 \% des Stadtgebietes (BLN 1982).

Berlin befindet sich im Übergangsbereich zwischen ozeanischem und kontinentalem Klimaeinfluß. Der Jahresniederschlag beträgt im langjährigen Mittel $585 \mathrm{~mm}$, die langjährige Jahresmitteltemperatur liegt bei $8,5^{\circ} \mathrm{C}$. 


\section{UNTERSUCHUNGSMETHODEN UND -ZEITRÄUME}

Zur Kennzeichnung des Mikroklimas wurden an den Untersuchungsstandorten Licht- und Temperaturmessungen in Bodennähe durchgeführt. Die Belichtung der Flächen wurde mit einem Luxmeter (Gossen Panlux) am 14./15.06.1981 gemessen. Extremtemperaturmessungen wurden mit Minimum-Maximum-Thermometern vom 1.5. 1981 bis 16.5.1981 durchgeführt.

Zur Bestimmung des Wasser-, Poren- und Luftvolumens wurden an den 13 Standorten in derNähe der Bodenfallen und Vegetationsquadrate je fünf Proben mit einem $100 \mathrm{~cm}^{3}$ Stechzylinder aus den oberen $5 \mathrm{~cm}$ des Horizontes gezogen. Aufliegende Streu wurde vorher entfernt. Die Parameter wurden nach den gängigen bodenkundlichen Methoden bestimmt ( $\mathrm{vgl}$. SCHLICHTING et al. 1995). Zur Bestimmung des pH-Wertes wurden an den Standorten je fünf Beutelproben entnommen. Der pH wurde elektrometrisch in $0,01 \mathrm{M} \mathrm{CaCl}_{2}$-Lösung gemessen.

Die Angaben zu Anbau-, Vorfrucht und Biozideinsatz stammen von den jeweils zuständigen Landwirten. Dafür gilt mein besonderer Dank den Herren ERNST, QUALITZ und ZORN.

An den Standorten Hal1, Hal3, Hal5, Hal8, Hal9 und Hac1 wurde am 23./24.06.1981 die Vegetation nach der Methode von BRAUN-BLANQUET aufgenommen.

Die oberflächenaktiven Spinnen wurden mit Bodenfallen (BARBER 1931) erfaßt. Hierzu wurden pro Fangfläche 10 Kunststoffbecher (Höhe: $8 \mathrm{~cm}$, oberer Durchmesser: $7 \mathrm{~cm}$ ) so in den Boden eingegraben, daß der oberere Rand mit der Bodenoberfläche abschloß. Als Fang- und Konservierungsflüssigkeit diente eine 4 \%ige Formollösung, mit der die Becher zu ca. 1/3 gefüllt wurden. Zur Herabsetzung der Oberflächenspannung wurde der Fangflüssigkeit etwas handelsübliches Detergenz beigegeben, im Winter als Frostschutzmittel zusätzlich Kochsalz.

Die Fallen waren vom 1.4. bis zum 31.7.1981 und vom 1.10. bis zum 31.12.1981 fängig. 


\section{Geographische Lage}

In sechs Ortsteilen bzw. Stadtbezirken wurden insgesamt 13 Standorte untersucht. Die Standorte werden im Text wie folgt abgekürzt:

Hal 1: Halmfrucht, Winterroggen, Jagen 48 im Bezirk Spandau

Hal 2: Halmfrucht, Sommerroggen, nördl. NSG Großer Rohrpfuhl im Bezirk Spandau

Hal 3: Halmfrucht, Winterroggen, nördl. Osterquelle in einer Senke im Ortsteil Lübars

Hal 4: Halmfrucht, Winterroggen, nördl. Osterquelle auf einem Hügel im Ortsteil Lübars

Hal 5: Halmfrucht, Winterroggen, großes Feld, nahe Schichauweg im Ortsteil Marienfelde

Hal 6: Halmfrucht, Winterroggen, kleines Feld, am Waldrand im Ortsteil Marienfelde

Hal 7: Halmfrucht, Winterroggen, südl. Baumberge im Ortsteil Heiligensee Hal 8: Halmfrucht, Winterroggen, nördl. Ritterfelddamm im Ortsteil Kladow Hal 9: Halmfrucht, Winterroggen, östl. Potsdamer Chaussee, südl. Friedhof im Bezirk Gatow

Hac 1: Hackfrucht, Kartoffeln, nördl. Ritterfelddamm im Ortsteil Kladow Bra: Ackerbrache, im Bezirk Spandau, nördl. der Zufahrtsstraße zum Eiskeller

Agr 2: Agropyro-Rumicion, Ackerrain mit Hecke östl. des Grenzweges, südl. Blankenfelder Chaussee im Ortsteil Lübars

RuR2: Rumicio-Ranunculetum, Feldpfuhl nördlich des Standortes Hal 7 im Ortsteil Heiligensee

\section{Mikroklima}

Die Mittelwerte aus den Extremtemperaturmessungen koinzidieren nicht in jedem Fall mit den Lichtwerten. Zwar besitzt die Hecke (Agr2) auch die niedrigste mittlere Temperartur, die höchste wurde jedoch nicht am Feldpfuhl, sondern auf dem auf einem Osrücken stark exponiertem Halmfruchtfeld (Hal3) gemessen. Ansonsten zeigen stark bewachsene (Bra, Hal9), beschattete (Hal1, Hal2) oder zum Zeitpunkt der Mikroklimamessungen stark durchfeuchtete Standorte (Hal7, RuR2, Hal6) Temperaturmittelwerte unter $20^{\circ} \mathrm{C}$, während sie bei den anderen Standorten darüber liegen (Tab. 1). 
Tab. 1: Kennzeichnende mikroklimatische,bodenphysikalische und -chemische Parameter der Untersuchungsflächen auf Berliner Kulturfeldern. Temp=Bodentemperatur, $W V=$ Wasservolumen, $d_{F}=$ Dichte,

\begin{tabular}{|lrrrrrrrrrrrrr|}
\hline & Bra & Hal1 & Hal2 & Hal3 & Hal4 & Agr2 & Hal5 & Hal6 & Hal7 & RuR2 & Hal8 & Hal9 & Hac1 \\
\hline Licht (Lx) & 1050 & 1360 & 5022 & 5002 & 4950 & 754 & 5650 & 5239 & 5060 & 6250 & 4900 & 2100 & 1750 \\
\hline Temp $\left({ }^{\circ} \mathbf{C}\right)$ & 16,8 & 15,7 & 19,7 & 21,7 & 20,0 & 15,9 & 20,2 & 18,5 & 18,3 & 17,3 & 19,9 & 18,6 & 20,8 \\
\hline WV (\%) & 18,0 & 24,4 & 20,9 & 12,1 & 18,2 & 17,4 & 13,9 & 27,6 & 23,8 & 34,9 & 10,2 & 19,9 & 21,2 \\
\hline $\mathbf{d}_{\mathbf{F}}\left(\mathbf{g} / \mathrm{cm}^{3}\right)$ & 2,59 & 2,59 & 2,64 & 2,61 & 2,62 & 2,59 & 2,62 & 2,60 & 2,61 & 2,59 & 2,62 & 2,61 & 2,61 \\
\hline pH & 7,06 & 4,10 & 4,81 & 4,02 & 5,69 & 4,47 & 5,94 & 5,13 & 4,36 & 4,67 & 4,88 & 4,47 & 5,66 \\
\hline
\end{tabular}

\section{Böden}

Die Standorte in Gatow, Kladow und Lübars befinden sich im Bereich von Geschiebemergel-Hochflächen. Die typischen Böden für diese Grundmoränen sind Parabraunerden. In Heiligensee und Spandau hingegen wurden grundwassernahe Talsandflächen sowie Gleye und Anmoore durch Entwässerung anbaufähig nutzbar gemacht (BLUME 1981).

Da im Untersuchungsgebiet entweder reine Sandböden (Spandau, Gatow, Kladow, Heiligensee) bzw. mit Sand überdeckte Mergelböden (Lübars, Marienfelde) anstanden, ist das Wasservolumen (WV) mit Werten zwischen $10 \%$ und $30 \%$ relativ gering. Den höchsten Wert besitzt mit ca. $35 \%$ WV der Feldpfuhl in Heiligensee (RuR2). Danach folgen Felder, in deren Senken sich das Wasser aufgrund des mergeligen Untergrundes längere Zeit stauen kann. Die Standorte $\mathrm{Hal} \mathrm{1,} \mathrm{Hal} 6$ und $\mathrm{Hal} 7$ besitzen Wasservolumina, die über $20 \%$ liegen. Im Gelände ansteigende, höher gelegene Standorte sind die Standorte $\mathrm{Hal} 3$ und $\mathrm{Hal}$ 8, deren WV knapp über $10 \%$ liegen. Aufgrund der Bearbeitung sind die Böden ausnahmslos als dicht zu bezeichnen. Die Werte liegen um $2,6 \mathrm{~g} / \mathrm{cm}^{3}$, was der Dichte für rein mineralische Böden $\left(d_{F}=2,65 \mathrm{~g} / \mathrm{cm}^{3}\right)$ sehr nahe kommt.

Die $\mathrm{pH}$-Werte der untersuchten Standorte liegen zwischen 4 und 7 in einem Bereich zwischen "stark sauer" ( $\mathrm{Hal} 3)$ und "neutral" (Bra).

\section{Feldfrüchte und Biozideinsatz}

InTab. 2 sind Angaben zu den im Untersuchungsjahrangebauten Feldfrüchten, zur Vorfrucht sowie zu Art und Zeitpunkt von Biozideinsätzen aufgelistet. Leere Spalten bedeuten, daß die jeweiligen Maßnahmen nicht angewandt wurden. 
Mit Ausnahme der Standorte Hal2 und Hac1 wurde auf allen Feldern Winter-Roggen angebaut. Als Vorfrucht wurde mit Ausnahme der Standorte Hal1 und Hal2 vom zuständigen Landwirt dieselbe Feldfrucht angegeben.

An Herbiziden wurde vor allem Tribunil gegen Windhalm ausgebracht (vgl. Tab. 2). Es wurde auf den Getreidefeldern Hal1 bis Hal7, mit Ausnahme von Hal6 angewandt, der im Herbst 1980 stark überschwemmt war, so daß auf einen Einsatz verzichtet werden mußte. Auf den Spandauer Feldern (Hal1 und Hal2) wurde noch ein weiteres Präparat angewandt, auf dem Heiligenseer Feld (Hal7) noch drei weitere, so daß dieses auch vom Herbizideinsatz her als das am intensivsten bearbeitete gelten muß. Auf den Kladower und Gatower Feldern (Hal8, Hal9 und Hac1) wurde auf einen Biozideinsatz verzichtet. Insektizide werden auf den Berliner Feldern nicht ausgebracht.

\section{Vegetation}

An sechs Standorten wurden Vegetationsaufnahmen nach der Schätzmethode von BRAUN-BLANQUET durchgeführt. Auffällig ist die insgesamt geringe bis sehr geringe Deckung der Wildkräuter auf den Feldern Hal1, Hal3 und Hal5, was höchstwahrscheinlich auf den Herbizideinsatz zurückzuführen ist (Tab. 3).

Auf den Kladower und Gatower Feldern ist der Deckungsgrad erheblich größer, wobei dies von nur einer Art (auf den Halmfruchtfeldern von Apera spica-venti, auf dem Hackfruchtfeld von Chenopodium album) hervorgerufen wird. Die Wildkrautgesellschaften werden daher auch als Aperatalia- (Hal5, Hal8) bzw. Polygono-Chenopodietalia-Gesellschaften charakterisiert. Im Falle des Feldes Hal9 ist durch das häufigere Auftreten der Quecke (Agropyron repens) eine Tendenz zur Verbrachung zu erkennen, so daß ein Übergang von Aperatalia- zu Agropyron-Gesellschaften erkennbar ist. Auf den beiden Halmfruchtfeldern Hal1 und $\mathrm{Hal} 3$ konnte aufgrund der bei allen Arten sehr niedrigen Deckungsgrade keine Zuordnung zu bestimmten Wildkrautgesellschaften vorgenommen werden. 
Tab. 2: Anbaufrüchte und Biozideinsatz auf den Ackerstandorten. $F=$ Frühjahr, $H=$ Herbst, Römische Zahlen = Monate

\begin{tabular}{|c|c|c|c|c|c|c|c|c|c|c|}
\hline & Hal1 & Hal2 & $\mathrm{Hal3}$ & Hal4 & Hal5 & Hal6 & Hal7 & Hal8 & Hal9 & Hac1 \\
\hline Anbaufrucht & $\begin{array}{l}\text { Winter- } \\
\text { Roggen }\end{array}$ & $\begin{array}{l}\text { Sommer- } \\
\text { Roggen }\end{array}$ & $\begin{array}{l}\text { Winter- } \\
\text { Roggen }\end{array}$ & $\begin{array}{l}\text { Winter- } \\
\text { Roggen }\end{array}$ & $\begin{array}{l}\text { Winter- } \\
\text { Roggen }\end{array}$ & $\begin{array}{l}\text { Winter- } \\
\text { Roggen }\end{array}$ & $\begin{array}{l}\text { Winter- } \\
\text { Roggen }\end{array}$ & $\begin{array}{l}\text { Winter- } \\
\text { Roggen }\end{array}$ & $\begin{array}{l}\text { Winter- } \\
\text { Roggen }\end{array}$ & Kartoffeln \\
\hline Vorfrucht & $\begin{array}{l}\text { Lolium- } \\
\text { Grassaat }\end{array}$ & $\begin{array}{l}\text { Lolium- } \\
\text { Grassaat }\end{array}$ & $\begin{array}{l}\text { Winter- } \\
\text { Roggen }\end{array}$ & $\begin{array}{l}\text { Winter- } \\
\text { Roggen } \\
\text { Grünkohl }\end{array}$ & $\begin{array}{l}\text { Winter- } \\
\text { Roggen, } \\
\text { Grünkohl }\end{array}$ & $\begin{array}{l}\text { Winter- } \\
\text { Roggen, }\end{array}$ & $\begin{array}{l}\text { Winter- } \\
\text { Roggen }\end{array}$ & $\begin{array}{l}\text { Winter- } \\
\text { Roggen }\end{array}$ & $\begin{array}{l}\text { Winter- } \\
\text { Roggen }\end{array}$ & $\begin{array}{l}\text { Winter- } \\
\text { Roggen }\end{array}$ \\
\hline \multicolumn{11}{|l|}{ Herbizide } \\
\hline Tribunil & $\bar{x}$ & $\bar{x}$ & $\bar{x}$ & $\bar{x}$ & $\mathrm{X}(\mathrm{im} \mathrm{H})$ & & $X(\mathrm{im} \mathrm{H})$ & & & \\
\hline Hedronal DP & $X$ (in IV) & $X$ (in IV) & & & & & & & & \\
\hline M52 & & & & & & & $X(\operatorname{im~F})$ & & & \\
\hline MP 58 & & & & & & & $X(\operatorname{im~F})$ & & & \\
\hline Bayleton & & & & & & & $X(\operatorname{im} F)$ & & & \\
\hline
\end{tabular}

Tab. 3: Allgemeine Daten zu den Vegetationsaufnahmen an ausgewählten Berliner Ackerstandorten

\begin{tabular}{|l|cccccc|}
\hline & Hal1 & Hal3 & Hal5 & Hal8 & Hal9 & Hac1 \\
\hline Aufnahmefläche in $\mathbf{~}^{2}$ & 20 & 20 & 20 & 10 & 10 & 10 \\
\hline Höhe der Krautschicht in $\mathbf{m}$ & 0,7 & 0,6 & 0,8 & 0,9 & 0,9 & 0,6 \\
\hline Deckung der Krautschicht & $<1 \%$ & $<1 \%$ & $30 \%$ & $60 \%$ & $70 \%$ & $75 \%$ \\
\hline
\end{tabular}




\section{ERGEBNISSE}

Tab.4 enthält die Artenliste mit Angabe der Individuenzahlen, desökologischen Typs (ÖT), des bevorzugten Stratums (ST), derPflanzenformation, in der die Art schwerpunktmäßig auftritt (SP) und die Größenklasse (GK). Die Nomenklatur richtet sich nach PLATEN etal. (1995). Der folgende Schlüssel erläutert die in Tab. 4 verwendeten Abkürzungen.

\section{Erläuterung der Abkürzungen}

a) Ökologischer Typ (ÖT):

TRETZEL (1952) stellte als erster ein System von ökologischen Typen auf, das er aus dem Verteilungsmuster der Spinnenarten im Freiland ableitete. In PLATEN et al. (1991) wird eine Modifikation dieser ökologischen Typen vorgestellt. Der ökologische Typ stellt das schwerpunktmäßige Auftreten einer Art unter der Einwirkung der unterschiedlichsten abiotischen und biotischen Faktoren im Freiland dar und wird als eine Art Etikett benutzt. Er sagt nichts über das im Labor ermittelte physiologische Optimum der Art hinsichtlich bestimmter Einzelfaktoren (Licht, Feuchte, Temperatur) bzw. deren Kombinationen aus. Allein die Tatsache, daß eine bestimmte Art immerwieder sehrhäufig auf unbewaldeten, trockenen Standorten gefunden wird, führt zu der Einschätzung "xerophile Freiflächenart" (ökologischer Typ „x").

Mit den ökologischen Typen soll versucht werden, die Bevorzugung der Arten für eine bestimmte Kombination der abiotischen Faktoren Licht, Temperatur und Feuchte im Freiland in ein überschaubares System zu bringen.

Die folgenden Artengruppen werden unterschieden:

Arten unbewaldeter Standorte:

$\mathrm{h}=$ hygrobiont/phil (in offenen Mooren, Naßwiesen, Anspülicht, etc.)

(h) = überwiegend hygrophil (auch in trockneren Lebensräumen: Frischwiesen, Weiden, etc.)

eu = euryöker Freiflächenbewohner (lebt in allen unbewaldeten Lebensräumen relativ unabhängig von der Feuchtigkeit des Habitats)

$x \quad=$ xerobiont-phil (auf Sandtrockenrasen, in trockenen Ruderalbiotopen, CallunaHeiden, etc.)

(x) = überwiegend xerophil (auch in feuchteren Lebensräumen, Arten der Äcker). In Frischwiesen und Weiden treten Arten dieses ÖT oft gemeinsam mit denen des ÖT „(h)“ auf. Im Gegensatz zu diesen findet man sie jedoch niemals in hoher Anzahl in feuchteren Lebensräumen.

hal $=$ halobiont/-phil (an Salzstellen) 
Arten bewaldeter Standorte (Wälder, Parks, Gebüsche, etc.):

$\mathrm{w}=$ euryöke Waldart (lebt in Wäldern gleich welchen Feuchtigkeitsgrades)

hw = in Feucht- und Naßwäldern (Erlen-, Birkenbruch-Gesellschaften, TraubenkirschenEschenwäldern, etc.)

(h)w = in mittelfeuchten Laubwäldern (Buchen-, Eichen-Hainbuchenwäldern, etc.)

$(\mathrm{x}) \mathrm{w}$ = in bodensauren Mischwäldern (Kiefern-Eichenwäldern, Kiefern-Forsten, KiefernBirkenwäldern auf mineralischen Böden, etc.)

arb $=$ arboricol (auf Bäumen und Sträuchern)

$\mathrm{R} \quad=$ an/unterRinde

Arten mit Schwerpunktvorkommen in bewaldeten oder unbewaldeten Biotoptypen:

(w) = Je nach Scherpunktvorkommen: überwiegend in Wäldern oder überwiegend in Freiflächen.

$h(w)=$ Je nach Schwerpunktvorkommen: überwiegend in Feucht und Naßwäldern oder nassen Freiflächen-Standorten.

$(h)(w)=$ Je nach Schwerpunktvorkommen: überwiegend in mittelfeuchten Laubwäldern oder feuchten Freiflächen.

$(x)(w)=$ Je nach Schwerpunktvorkommen: überwiegend in bodensauren Mischwäldern oder trockenen Freiflächen.

Spezielle Lebensräume und Anpassungen:

sko = skotobiont/phil (in Höhlen, Kleintierbauten, Kellern, etc.)

syn = synanthropim engeren Sinne (an und in Gebäuden, Bauwerken, Kellern, Ställen, etc.)

th = thermophil (an Standorten mit hoher Insolation) incl. der "diplo-stenöken" Arten. Hierunter ist das Vorkommen von Arten zu verstehen, die in offenen, nassen und trockenen Lebensräumen auftreten, in Lebensräumen mittlerer Feuchtigkeit dagegen fehlen. Da sich diese Lebensräume bezüglich ihrer Sonneneinstrahlung und damit in inrem Wärmehaushalt ähneln („Steppen“im Sinne von PEUS 1950), scheint für das Vorkommen dieser Arten der Temperaturfaktor ausschlaggebend zu sein (BRAUN 1969).

b) Schwerpunktvorkommen (SP):

Um die Verteilung der Spinnenarten in Abhängigkeit von ihren ökologischen Ansprüchen systematisieren zu können, wurden die Biotoptypen Berlins in 14 Pflanzenformationen und eine Sparte „synanthrope Standorte“ zusammengefaßt. Die Pflanzenformationen repräsentieren unterschiedliche synsystematische Einheiten, sie können Klassen (z.B. Formation 2) als auch Assoziationen (z.B. Formation 9) umfassen. Die Pflanzenformationen wurden aus KORNECK \& SUKOPP (1988) übernommen. Die Auswertung in Kap. "Die Verteilung der Arten und Individuen auf die ökologischen Typen und Pflanzenformationen" basiert auf einer Verknüpfung der Spinnenarten mit bestimmten Pflanzenformationen. Dabei wurde als Schwerpunktvorkommen einer Art diejenige Pflanzenformation gewählt, in der die Art am häufigsten zu finden war (vgl. PLATEN et al. 1991) 
Im folgenden Schlüssel sind nur diejenigen aufgeführt, die in der Tab. 4 vorkommen.

$1=$ Hygrophile Therophytenfluren

Auf periodisch trockenfallenden Teichböden und Fließgewässerbetten, vegetationsfreien Ufern und Kiesgruben. Isoëto-Nanojuncetea, Bidentetea tripartitae.

2 = Oligotrophe und mesotrophe Verlandungsvegetation Oxycocco-Sphagnetea, Scheuchzerio-Caricetea fuscae, nährstoffarme Verlandungsmoore (einschl. Kiefern- und Birken-Gehölzgesellschaften).

$3=$ Eutrophe Verlandungsvegetation

Phragmition, Glycerion fluitantis, Magnocaricion elatae.

$4=$ Feucht- und Naßwiesen

Feuchtes Wiesengrünland, Molinietalia, Cirsio-Polygonetum.

$5=$ Frischwiesen und - weiden

Wirtschaftsgrünland frischer bis mäßig trockener Standorte, Parkanlagen, Arrhenatheretalia.

$7=$ Feucht- und $\mathrm{Naß}$ wälder

Erlenbruchwälder, Traubenkirschen-Eschenwälder, Birkensumpfwälder, Weidengebüsche der Flußufer, Alnetea glutinosae, Alno-Padion.

$8=$ Mesophile Fallaubwälder

Stieleichen-Hainbuchenwald, Traubeneichen-Hainbuchenwald, Schattenblumen-und Labkraut-Buchenwälder und die sie ersetzenden Forsten auf mäßig trockenen bis feuchten Standorten.

$9=$ Bodensaure Laub- und Nadelwälder

Kiefern-Traubeneichenwälder, Buchen-Eichenwälder, Birken-Eichenwälder und die sie ersetzenden Forsten, Quercetea robori-petraeae, Luzulu-Fagion sylvaticae.

$10=$ Subatlantische Ginsterheiden

Calluno-Genistion.

11 = Sandtrockenrasen, Halbtrockenrasen, Magerrasen

Kräuter- und Grasfluren trockenwarmer Standorte, Sandtrockenrasen der Binnendünen, Sedo-Scleranthetea, Festuco-Brometea.

$12=$ Quecken-Trockenfluren

Halbruderale Quecken-Trockenfluren an Straßen- und Wegrändern, auf alten Gartenund Ackerbrachen, Agropyretea intermedii-repentis.

$13=$ Ausdauernde Ruderalfluren

Artemisietea, Galio-Urticetea.

$14=$ Ackerunkrautfluren und kurzlebige Ruderalvegetation

Secalinetea, Chenopodietea, Sisymbrietea.

$15=$ Synanthrope Standorte

In und an Bauwerken und Gebäuden, in Kellern. 
Tab. 4: Liste der Webspinnen auf Berliner Kulturflächen mit Angaben zur Biologie und Ökologie.

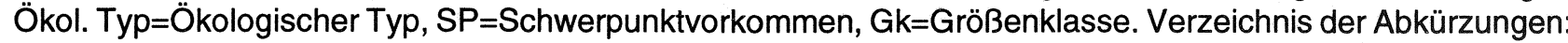
s. S. 9-11 und 18.

\begin{tabular}{|c|c|c|c|c|c|c|c|c|c|c|c|c|c|c|c|c|}
\hline \multirow[b]{2}{*}{ Familie/Art } & \multicolumn{13}{|c|}{ FALLENSTANDORTE } & \multirow[b]{2}{*}{ Ökol. Typ } & \multirow[b]{2}{*}{ SP } & \multirow[b]{2}{*}{ GK } \\
\hline & Bra & Hal 1 & Hal 2 & Hal 3 & Hal 4 & Agr 2 & Hal 5 & Hal 6 & RuR 2 & Hal 7 & Hal 8 & Hal 9 & Hac 1 & & & \\
\hline \multicolumn{17}{|l|}{ Mimetidae-Spinnenfresser } \\
\hline Ero furcata (Villers, 1789) & & & & & & & & & 3 & & & & & $(x)(w)$ & 9 & 2 \\
\hline & & & & & & & & & & & & & & & & \\
\hline \multicolumn{17}{|l|}{ Theridiidae - Kugelspinnen } \\
\hline Achaearanea riparia (Blackwall, 1834) & & & & 1 & & & & & 2 & & & & & $(x)$ & 13 & 2 \\
\hline Enoplognatha ovata (Clerck, 1757) & & & & & & 2 & & & & & & & & $(x)(w)$ & 9 & 2 \\
\hline Enoplognatha thoracica (Hahn, 1833) & & & & & 1 & 1 & & & & & & & & $(x)(w)$ & 11 & 2 \\
\hline Euryopis flavomaculata (C. L. Koch, 1836) & & & & & & & & & & & 1 & & & $(x)(w)$ & 9 & 2 \\
\hline Robertus lividus (Blackwall, 1836) & 1 & 16 & 2 & 1 & 2 & 10 & & 1 & & 1 & & & & $(x) w$ & 9 & 2 \\
\hline Robertus neglectus (O. Pickard-Cambridge, 1871) & 1 & & & & & & & & & & & & & (h)w & 8 & 2 \\
\hline Theridion bimaculatum (Linnaeus, 1767) & & & & & & 1 & & & & & 1 & & & $(x)(w)$ & 9 & 2 \\
\hline & & & & & & & & & & & & & & & & \\
\hline \multicolumn{17}{|l|}{ Linyphiidae - Zwerg- und Baldachinspinnen } \\
\hline Allomengea scopigera (Grube, 1859) & 3 & & & & & & & & & & & & & $\mathrm{~h}$ & 4 & 2 \\
\hline Araeoncus humilis (Blackwall, 1841) & 46 & 13 & 41 & 24 & 25 & 2 & 135 & 54 & 19 & 134 & 19 & 62 & 30 & $(x)$ & 14 & 1 \\
\hline Bathyphantes approximatus (O. P.-Cambridge, 1871) & & & & & & 1 & & & & & & & & $h(w)$ & 7 & 2 \\
\hline Bathyphantes gracilis (Blackwall, 1841) & 39 & 5 & 52 & 10 & 13 & 42 & 53 & 21 & 46 & 43 & 2 & 26 & 185 & $\mathrm{eu}$ & 14 & 2 \\
\hline Bathyphantes parvulus (Westring, 1851) & 5 & 1 & 1 & & 6 & 169 & & 4 & 7 & 9 & & 2 & 4 & eu & 13 & 2 \\
\hline Centromerita bicolor (Blackwall, 1833) & 456 & 2 & 3 & & & 49 & & 3 & & 1 & & 9 & 8 & $(x)(w)$ & 12 & 2 \\
\hline Centromerita concinna (Thorell, 1875) & 68 & & & & 1 & 10 & & 1 & & & 4 & 1 & 1 & $(x)(w)$ & 9 & 2 \\
\hline Centromerus pabulator (O. Pickard-Cambridge, 1875) & 1 & & & & & & 1 & 1 & & & & & & $(x)(w)$ & 9 & 2 \\
\hline Centromerus sylvaticus (Blackwall, 1841) & 35 & 6 & 13 & & & 79 & & 1 & & & & 6 & 4 & (h)w, arb & 8 & 2 \\
\hline Ceratinella brevis (Wider, 1834) & & & & & 1 & 19 & & & & & & & & (h)w & 9 & 2 \\
\hline Ceratinopsis stativa (Simon, 1881) & & & & & & & 1 & & & & & & & (h),th & 5 & 2 \\
\hline Dicymbium brevisetosum Locket, 1962 & 87 & 3 & 2 & 2 & 1 & 22 & 3 & 1 & 1 & 3 & 1 & 2 & 1 & eu & 12 & 2 \\
\hline Diplocephalus cristatus (Blackwall, 1833) & 1 & 1 & & 8 & 9 & 1 & 1 & & & 4 & 1 & 2 & 13 & $(x)$ & 12 & 1 \\
\hline Diplocephalus latifrons (O. Pickard-Cambridge, 1863) & & 2 & 1 & & & & & & & 1 & & & & (h)w & 8 & 1 \\
\hline Diplocephalus picinus (Blackwall, 1841) & & & & 1 & 2 & 2 & 2 & 4 & & & & 3 & & $(x) w$ & 9 & 1 \\
\hline Diplostyla concolor (Wider, 1834) & 2 & 2 & 1 & 2 & 4 & 57 & 7 & 1 & 1 & 2 & 3 & 9 & 7 & (h) $(w)$ & 7 & 2 \\
\hline
\end{tabular}




\begin{tabular}{|c|c|c|c|c|c|c|c|c|c|c|c|c|c|c|c|c|}
\hline \multirow[b]{2}{*}{ Familie/Art } & \multicolumn{13}{|c|}{ FALLENSTANDORTE } & \multirow[b]{2}{*}{ Ökol. Typ } & \multirow[b]{2}{*}{ SP } & \multirow[b]{2}{*}{ GK } \\
\hline & Bra & Hal 1 & Hal 2 & Hal 3 & Hal 4 & Agr 2 & Hal 5 & Hal 6 & RuR 2 & Hal 7 & Hal 8 & Hal 9 & Hac 1 & & & \\
\hline \multicolumn{17}{|l|}{ Linyphiidae-Zwerg- und Baldachinspinnen } \\
\hline Erigone atra Blackwall, 1833 & 558 & 382 & 177 & 336 & 400 & 60 & 1258 & 773 & 283 & 1022 & 291 & 348 & 477 & eu & 14 & 2 \\
\hline Erigone dentipalpis (Wider, 1834) & 429 & 330 & 279 & 321 & 357 & 34 & 715 & 474 & 185 & 636 & 456 & 216 & 331 & eu & 14 & 2 \\
\hline Erigone longipalpis (Sundevall, 1830) & 8 & 1 & 2 & 7 & 19 & & 29 & 28 & 107 & 90 & & 2 & & $(\mathrm{x})$, hal & 14 & 2 \\
\hline Erigonella hiemalis (Blackwall, 1841) & & 1 & & & & & & & & & & & & $(h)(w)$ & 4 & 1 \\
\hline Gnathonarium dentatum (Wider, 1834) & & & & & & & 2 & & 8 & 4 & & & & $\mathrm{~h}$ & 1 & 2 \\
\hline Gonatium rubens (Blackwall, 1833) & 1 & & 1 & & & & & & & & & & & $(x) w$ & 9 & 2 \\
\hline Gongylidium rufipes (Linnaeus, 1758) & & & & & & & & & & & & & 5 & $(h)(w)$ & 8 & 2 \\
\hline Hylyphantes graminicola (Sundevall, 1830) & & & & & & & & & 1 & & & & & $h(w)$, arb & 7 & 2 \\
\hline Hypomma bituberculatum (Wider, 1834) & & & 1 & 1 & & & & & & 1 & & & & $\mathrm{~h}$ & 3 & 2 \\
\hline Lepthyphantes angulipalpis (Westring, 1851) & & & & & & 1 & & & & & & & & $(x) w$ & 9 & 2 \\
\hline Lepthyphantes flavipes (Blackwall, 1854) & & 1 & 2 & & & 1 & 1 & 2 & 1 & & & & 1 & (x)w, sko & 9 & 2 \\
\hline Lepthyphantes mengei Kulczynski, 1887 & 2 & & & & & & & & & & & & & $h(w)$ & 2 & 1 \\
\hline Lepthyphantes pallidus(O. Pickard-Cambridge, 1871) & & & & & & 6 & 1 & & & & & 2 & & $(h)(w)$ & 8 & 2 \\
\hline Lepthyphantes tenebricola (Wider, 1834) & & & & 2 & & & & & & & & & 1 & (h)w & 8 & 2 \\
\hline Lepthyphantes tenuis (Blackwall, 1852) & 3 & 2 & 4 & 2 & 8 & 5 & 11 & 7 & 1 & 3 & 1 & 18 & 28 & (x) & 13 & 2 \\
\hline Linyphia hortensis Sundevall, 1830 & & & & & & 3 & & 1 & & 1 & & 1 & & (h)w & 8 & 2 \\
\hline Macrargus carpenteri (O. Pickard-Cambridge, 18894) & & 2 & & & & & & & & & & & & $(x) w$ & 9 & 2 \\
\hline Macrargus rufus (Wider, 1834) & & 10 & & & & & & & & & & & & $(\mathrm{x}) \mathrm{w},(\mathrm{arb})$ & 9 & 2 \\
\hline Meioneta beata (O. Pickard-Cambridge, 1906) & 1 & & & & & & & & & & & & & $x$ & 11 & 1 \\
\hline Meioneta fuscipalpis (C. L. Koch, 1836) & & & & & & & 1 & & & & & & 1 & $(x)$ & 12 & 1 \\
\hline Meioneta rurestris (C. L. Koch, 1836) & 1 & 25 & 9 & 41 & 93 & 1 & 122 & 72 & 9 & 46 & 77 & 28 & 96 & (x) & 14 & 2 \\
\hline Micrargus herbigradus (Blackwall, 1854) & 3 & 6 & 9 & 3 & 1 & 1 & & & & 1 & & 2 & & $(x) w$ & 9 & 2 \\
\hline Microlinyphia pusilla (Sundevall, 1830) & 1 & 1 & & & & & 1 & & & 2 & 1 & & 1 & eu & 4 & 2 \\
\hline Microneta viaria (Blackwall, 1841) & & & 2 & & & & & & & & & & & (h)w & 8 & 2 \\
\hline Neriene clathrata (Sundevall, 1830) & 1 & & & & & 2 & & & & & & & & (h)w & 8 & 2 \\
\hline Oedothorax apicatus (Blackwall, 1850) & 1393 & 99 & 124 & 178 & 217 & 3 & 375 & 172 & 12 & 41 & 388 & 334 & 510 & $x$ & 14 & 2 \\
\hline Oedothorax fuscus (Blackwall, 1834) & 317 & 6 & 22 & 34 & 41 & 2 & 207 & 41 & 161 & 219 & 11 & 7 & 22 & eu & 4 & 2 \\
\hline Oedothorax gibbosus (Blackwall, 1841) & & & & & & & 1 & & & 1 & & & & $\mathrm{~h}$ & 2 & 2 \\
\hline Oedothorax retusus (Westring, 1851) & 534 & 17 & 59 & 65 & 138 & 21 & 86 & 57 & 9 & 63 & 44 & 193 & 6 & eu & 4 & 2 \\
\hline Ostearius melanopygius (O. Pickard-Cambridge, 1879) & & & 2 & & & & 2 & & & & & & 42 & $x$ & 14 & 2 \\
\hline Pelecopsis parallela (Wider, 1834) & 7 & 6 & 2 & 4 & 3 & & 5 & 1 & & & 3 & 1 & 1 & $(x)$ & 11 & 1 \\
\hline Peponocranium orbiculatum (O. P.-Cambridge, 1882) & & & 1 & & & & & & & & & & & $(x) w$ & 9 & 1 \\
\hline Pocadicnemis pumila (Blackwall, 1841) & 4 & 2 & 3 & & 2 & 52 & & & & & & 2 & & $\mathrm{eu}$ & 13. & 1 \\
\hline
\end{tabular}




\begin{tabular}{|c|c|c|c|c|c|c|c|c|c|c|c|c|c|c|c|c|}
\hline & \multicolumn{13}{|c|}{ FALLENSTANDORTE } & \multirow[b]{2}{*}{ ökol. Typ } & \multirow[b]{2}{*}{ SP } & \multirow[b]{2}{*}{ GK } \\
\hline Familie/Art & Bra & Hal 1 & Hal 2 & Hal 3 & Hal 4 & Agr 2 & Hal 5 & Hal 6 & RuR 2 & Hal 7 & Hal 8 & Hal 9 & Hac 1 & & & \\
\hline Linyphiidae-Zwerg- und Baldachinspinnen & & & & & & & & & & & & & & & & \\
\hline Porrhomma convexum (Westring, 1851) & & & & & & & & & 1 & & & & & sko & $?$ & 2 \\
\hline Porrhomma microphthalmum (O. P.-Cambridge, 1871) & & & & & & & & & & & 1 & & 1 & $(x)$ & 14 & 2 \\
\hline Porrhomma pygmaeum (Blackwall, 1834) & & & & & & & 1 & & & & & & & $h(w)$ & 7 & 1 \\
\hline Savignia frontata (Blackwall, 1833) & 2 & . & 1 & & 1 & & 6 & & & 11 & & 1 & 1 & $\mathrm{~h}$ & 4 & 1 \\
\hline Silometopus elegans (O. Pickard-Cambridge, 1872) & & 3 & & & & & & & & & & 3 & & $\mathrm{~h}$ & 2 & 1 \\
\hline Silometopus reussi (Thorell, 1871) & 3 & 1 & & 32 & 5 & 9 & 1 & & & & & & 1 & $x$ & 14 & 1 \\
\hline Stemonyphantes lineatus (Linnaeus, 1758) & 1 & 14 & 4 & & 3 & 8 & & 3 & & & 1 & & & $(x)$ & 13 & 2 \\
\hline Syedra myrmicarum (Kulczynski, 1882) & & & & & 1 & & & 1 & & & & & & $x$ & $?$ & 1 \\
\hline Tapinocyba insecta (L. Koch, 1869) & & 4 & 2 & & & & & & & & & & & $(x) w$ & 9 & 1 \\
\hline Tiso vagans (Blackwall, 1834) & 18 & & 2 & 1 & 2 & 6 & 1 & 1 & & & & 1 & & (h) & 4 & 2 \\
\hline Troxochrus scabriculus (Westring, 1851) & 41 & 1 & 1 & 2 & 3 & 22 & & 6 & & & & 3 & 1 & $x$ & 11 & 1 \\
\hline Walckenaeria acuminata Blackwall, 1833 & & & 1 & & 1 & 1 & & & & & & 2 & & $(x) w$ & 9 & 2 \\
\hline Walckenaeria antica (Wider, 1834) & 6 & 1 & 1 & & & & & & & & & & & $(x)$ & 13 & 2 \\
\hline Walckenaeria atrotibialis (O. Pickard-Cambridge, 1878) & & & 1 & & & & & & & & & & & $(w)$ & 7 & 2 \\
\hline Walckenaeria dysderoides (Wider, 1834) & & & & & & & & & & & & 1 & & $(x) w$ & 9 & 1 \\
\hline Walckenaeria nudipalpis (Westring, 1851) & & & & & & & 1 & & & & & & & $\mathrm{~h}$ & 2 & 2 \\
\hline Walckenaeria unicornis O. Pickard-Cambridge, 1861 & & & & 1 & & 11 & & & & & & & & (h) & 2 & 2 \\
\hline & & & & & & & & & & & & & & & & \\
\hline Tetragnathidae - Streckerspinnen & & & & & & & & & & & & & & & & \\
\hline Metellina segmentata (Clerck, 1757) & & & & & & 1 & & & & & & & & $(h)(w)$ & 8 & 3 \\
\hline Pachygnatha clercki Sundevall, 1823 & 101 & & 2 & 1 & 4 & 10 & 60 & 10 & 16 & 11 & 1 & 4 & 1 & $\mathrm{~h}$ & 2 & 3 \\
\hline Pachygnatha degeeri Sundevall, 1830 & 940 & 66 & 35 & 50 & 100 & 365 & 29 & 52 & 2 & 100 & 11 & 45 & 4 & eu. & 11 & 2 \\
\hline Pachygnatha listeri Sundevall, 1830 & 2 & & 1 & & & & & & & & & & & hw & 7 & 2 \\
\hline Tetragnatha pinicola L. Koch, 1870 & & & & 2 & 3 & & 2 & & 1 & & & 1 & & $(x)$ & 14 & 3 \\
\hline & & & & & & & & & & & & & & & & \\
\hline Araneidae - Radnetzspinnen & & & & & & & & & & & & & & & & \\
\hline Araneus diadematus (Clerck, 1757) & & & 1 & & & & & & & & & & & $(x)(w)$ & 9 & 4 \\
\hline Araneus quadratus Clerck, 1757 & & & & & 1 & & & & & & & & & eu & 10 & 4 \\
\hline Cercidia prominens (Westring, 1851) & & 1 & & & & & & & & & & & & $w$ & $?$ & 2 \\
\hline Cyclosa oculata (Walckenaer, 1802) & & & & & 1 & & & & & & & & & eu,th & $?$ & 3 \\
\hline Mangora acalypha (Walckenaer, 1802) & & 2 & & 1 & & & 1 & & & & & & & $(x)$ & 14 & 2 \\
\hline
\end{tabular}




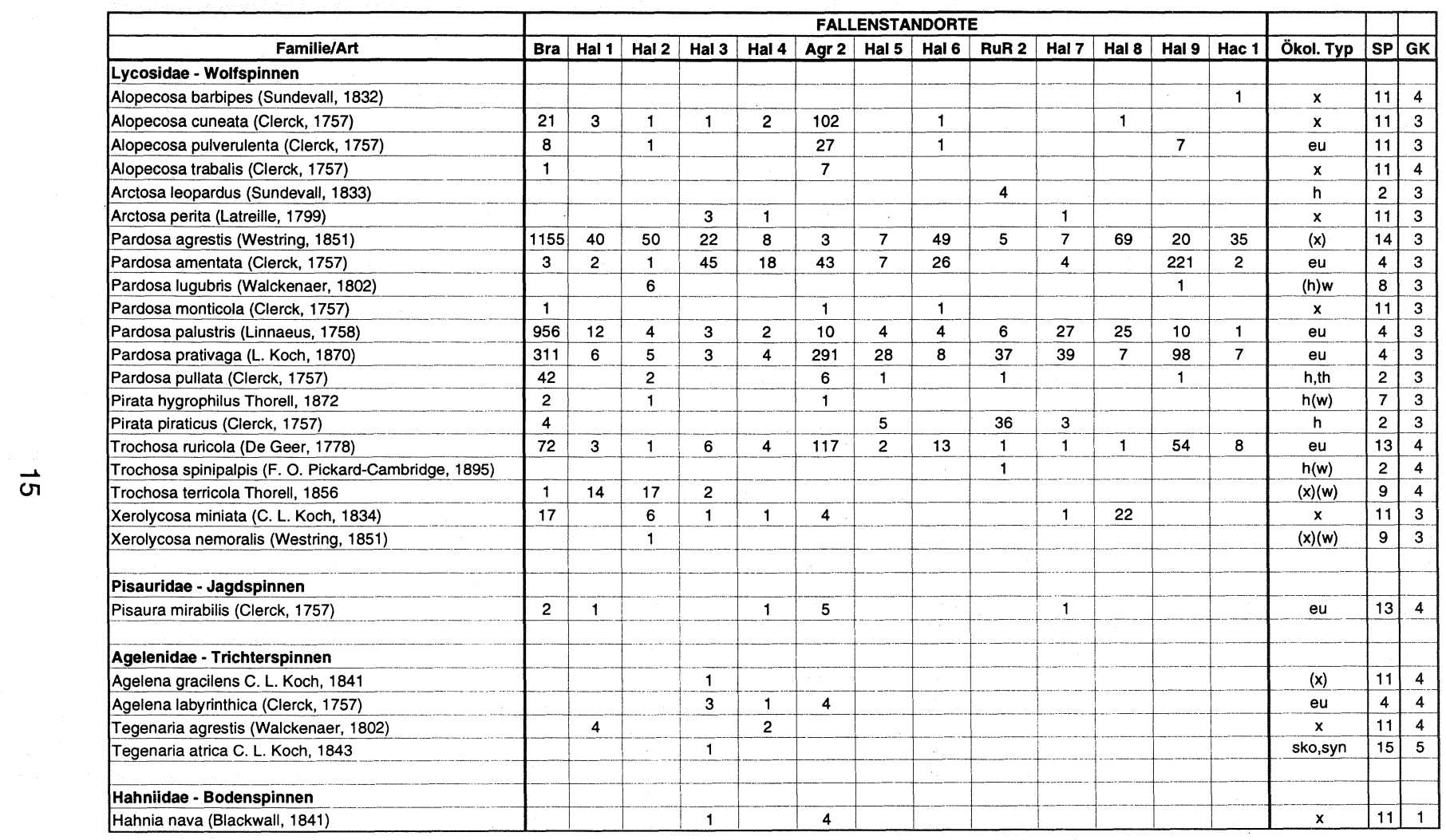




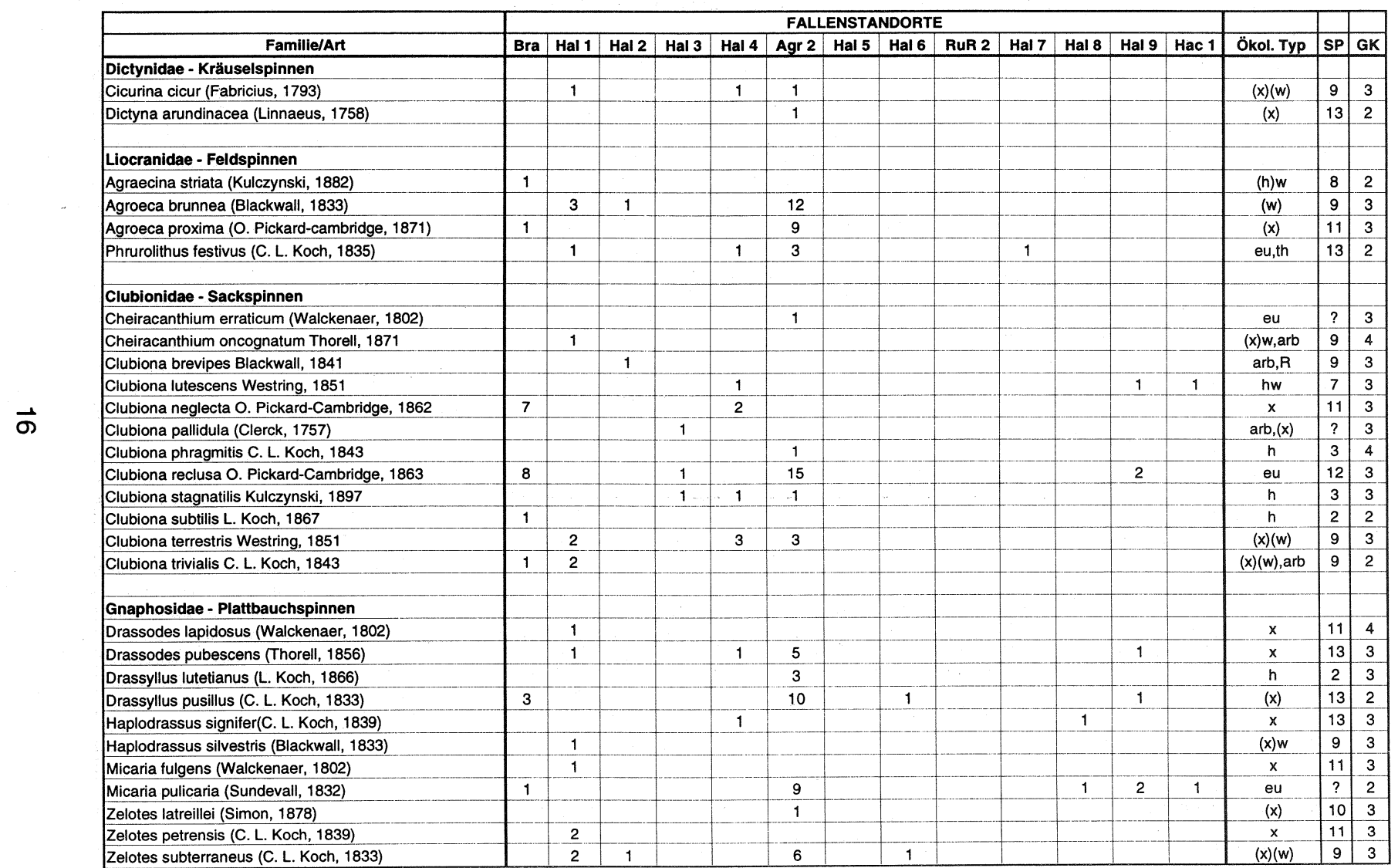




\begin{tabular}{|c|c|c|c|c|c|c|c|c|c|c|c|c|c|c|c|c|}
\hline \multirow[b]{2}{*}{ Familie/Art } & \multicolumn{13}{|c|}{ FALLENSTANDORTE } & \multirow[b]{2}{*}{ Ökol. Typ } & \multirow[b]{2}{*}{ SP } & \multirow[b]{2}{*}{ GK } \\
\hline & Bra & Hal 1 & Hal 2 & Hal 3 & $\mathrm{Hal} 4$ & Agr 2 & Hal 5 & Hal 6 & RuR 2 & Hal 7 & Hal 8 & Hal 9 & Hac 1 & & & \\
\hline \multicolumn{17}{|l|}{ Zoridae - Wanderspinnen } \\
\hline Zora silvestris Kulczynski, 1897 & & & & & & 1 & & & & & & & & $(x)(w)$ & 10 & 2 \\
\hline Zora spinimana (Sundevall, 1833) & 2 & 2 & 2 & & 1 & 35 & & & & & & & & eu & $?$ & 3 \\
\hline & & & & & & & & & & & & & & & & \\
\hline \multicolumn{17}{|l|}{ Philodromidae - Laufspinnen } \\
\hline Philodromus margaritatus (Clerck, 1757) & & 1 & & & & & & & & & & & & arb, $R$, th & 9 & 3 \\
\hline Tibellus oblongus (Walckenaer, 1802) & 2 & 1 & & & 1 & & & & & & & & 1 & $x$ & 11 & 3 \\
\hline & & & & & & & & & & & & & & & & \\
\hline \multicolumn{17}{|l|}{ Thomisidae-Krabbenspinnen } \\
\hline Ozyptila praticola (C. L. Koch, 1837) & & & & & & 1 & & & & & & 1 & & $(x) w$ & 9 & 2 \\
\hline Ozyptila trux (Blackwall, 1846) & & & & & & 1 & & 1 & & & & 3 & & $h(w)$ & 4 & 2 \\
\hline Xysticus cristatus (Clerck, 1757) & 49 & & & 1 & 1 & 22 & & & & & 1 & & 1 & $x$ & 13 & 3 \\
\hline Xysticus kochi Thorell, 1872 & 95 & 5 & & & 1 & 2 & & 2 & & 1 & 5 & & & $\mathrm{x}$ & 11 & 3 \\
\hline Xysticus robustus (Hahn, 1832) & & & & & & & & & & & 1 & & & $x$ & 10 & 3 \\
\hline Xysticus ulmi (Hahn, 1831) & 1 & & & 1 & 1 & 2 & & & & & & 1 & & $\mathrm{~h}$ & 2 & 3 \\
\hline & & & & & & & & & & & & & & & & \\
\hline \multicolumn{17}{|l|}{ Salticidae - Springspinnen } \\
\hline Euophrys frontalis (Walckenaer, 1802) & & & 1 & & & 1 & & & & & & & & $(x)(w)$ & 11 & 2 \\
\hline Evarcha arcuata (Clerck, 1757) & & 1 & & & & 1 & & & & & & & & eu & 2 & 3 \\
\hline Heliophanus flavipes Hahn, 1832 & 1 & & & & & & & & & & & & & $x,(a r b)$ & 11 & 2 \\
\hline Talavera aequipes (O. Pickard-Cambridge, 1871) & & & & & & 3 & & & & & & & & $\mathbf{x}$ & 11 & 2 \\
\hline Artenzahlen & 69 & 61 & 57 & 46 & 59 & 81 & 40 & 41 & 31 & 37 & 32 & 48 & 40 & & & \\
\hline Individuenzahlen & 7893 & 1148 & 971 & 1230 & 1530 & 1869 & 3176 & 1902 & 969 & 2536 & 1452 & 1761 & 1844 & & & \\
\hline
\end{tabular}


c) Größenklassen (GK)

ZurErmittlung der Körperlänge (ohne Anhänge) wurden eigene Messungen durchgeführt sowie Angaben aus der Literatur verwendet. Die Längenbereiche für Männchen und Weibchen wurden separat gemittelt und aus diesen Wertepaaren fürjede Art eine mittlere Größe berechnet. Diese wurde dann einer der fünf Größenklassen zugeordnet:

$\begin{array}{ll}1 & <2 \mathrm{~mm} \\ 2 & 2-4,9 \mathrm{~mm} \\ 3 & 5-9,9 \mathrm{~mm} \\ 4 & 10-14,9 \mathrm{~m} \\ 5 & >15 \mathrm{~mm}\end{array}$

\section{Der Arten- und Individuenbestand}

An den 13 Standorten wurden im Untersuchungszeitraum insgesamt 155 Spinnenarten in 23'281 Individuen nachgewiesen.

Der artenreichste Standort ist mit 81 Arten die Hecke (Agr2), der artenund individuenärmste (31 Arten mit 969 Individuen) derFeldpfuhl (RuR2). Die zweithöchste Artenzahl wurde mit 69 Arten in der Ackerbrache (Bra) ermittelt. Dieser Standort ist auch der individuenreichste (7893). Die Artenzahlen der Halmfruchtfelderliegen zwischen 32 (Hal8) und 61 (Hal1), die Individuenzahlen zwischen 971 (Hal2) und 3176 (Hal5), wobei die mit Herbiziden behandelten Flächen nicht durchgängig geringere Arten- und Individuenzahlen aufweisen als die unbehandelten Standorte. Die entspre-chenden Werte auf dem Hackfruchtfeld nehmen mit 40 Arten und 1844 Individuen eine Mittelstellung im Vergleich zu den Halmfruchtfeldern ein.

\section{Die Verteilung der Arten und Individuen auf die Spinnenfamilien}

Etwa die Hälfte aller Arten entfallen auf die Linyphiiden (Abb. 1). Danach folgen die Lycosiden, Clubioniden, Gnaphosiden und Theridiiden. Etwa ein Viertel aller Arten wird von den übrigen 12 nachgewiesenen Familien gestellt, die alle mit weniger als sieben Arten vertreten sind. Es sind dies (in absteigender Reihenfolge ihrer Artenzahlen: Thomisidae (6), Araneidae, Tetragnathidae (je 5), Agelenidae, Liocranidae, Salticidae (je 4), Dictynidae, Philodromidae, Zoridae (je 2) und Hahniidae, Mimetidae, Pisauridae (je 1 Art).

Das Artenverhältnis von Linyphiiden zu Lycosiden beträgt für alle Standorte 3,4:1 und liegt damit im Bereich von Halbtrocken- und Sandtrockenrasen (PLATEN 1989). Das Individuenverhältnis beträgt 4,8:1, wobei 


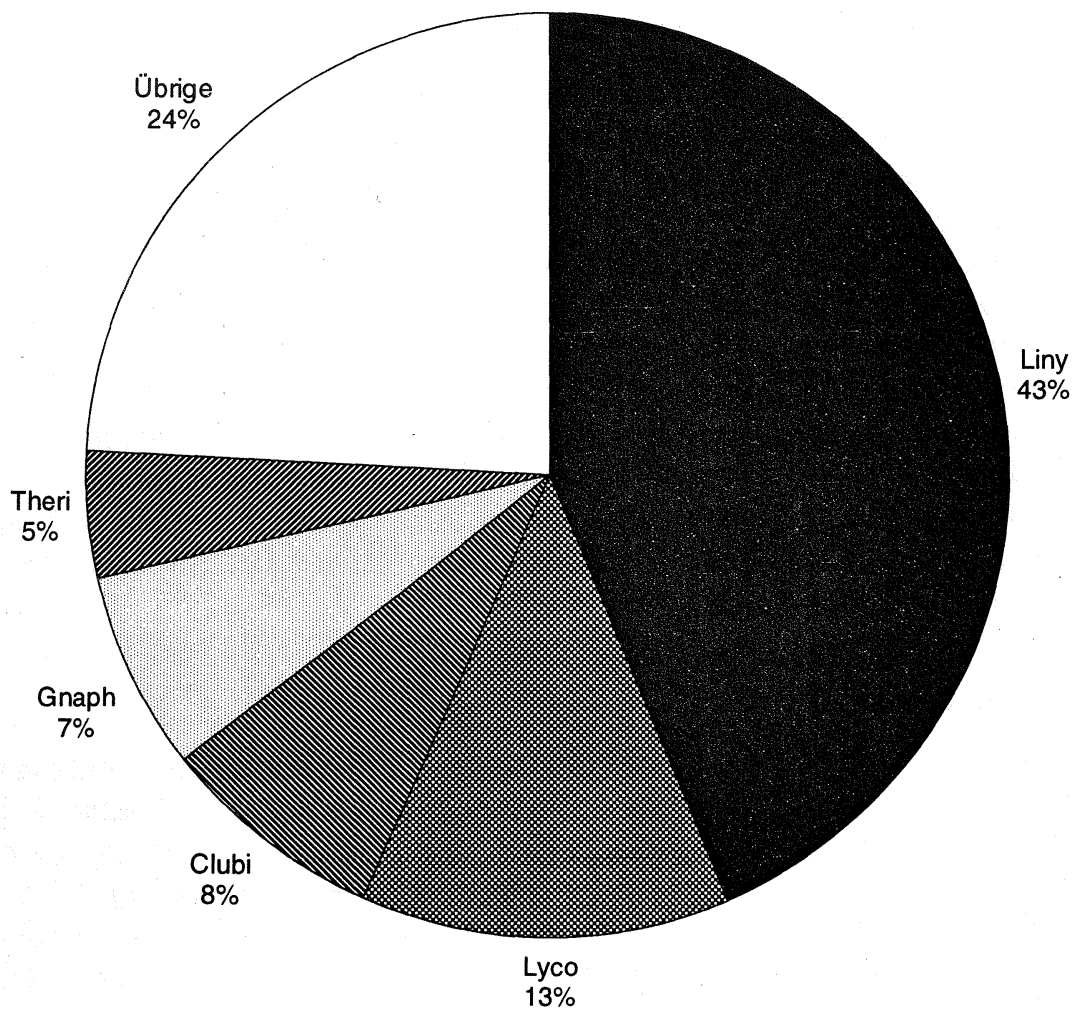

Abb. 1: Prozentuale Anteile der häufigsten Spinnenfamilien auf den untersuchten Berliner Kulturflächen. Theri = Theridiidae, Gnaph = Gnaphosidae, Clubi $=$ Clubionidae, Lyco $=$ Lycosidae, Liny $=$ Linyphiidae

die Streuung erheblich ist, wenn die Standorte nach Anbaufrucht bzw. Nutzungsintensität gruppiert werden.

Während dieses Verhältnis mit 1,5:1 bzw. 1,2:1 in der Ackerbrache (Bra) und der Hecke (Agr2) nahezu ausgeglichen ist, liegt es am HackfruchtStandort (Hac1) bei 33:1. Obwohl hier keine Herbizide eingesetzt werden, scheint sich die intensive Bodenbearbeitung (wiederholtes Anhäufeln) ungünstig auf die Aktivitätsdichte von Lycosiden auszuwirken, was sowohl bereits von HEYDEMANN (1953) als auch von KRAUSE (1987) festgestellt wurde.

Die Individuenverhältnisse der beiden Familien betragen in den Halmfruchtflächen für alle neun Standorte zusammengenommen 12,9:1. Betrachtet man die nicht herbizidhandelten und die behandelten getrennt, 
so zeigt sich im ersten Falle ein Individuenverhältnis von 15:1, im zweiten von $9,8: 1$. Dies überrascht zunächst, da eine Wirkung von Herbiziden auf die epigäisch aktiven Lycosiden am ehesten zu erwarten wäre. Zwar erhöhte sich die absolute Zahl der Lycosiden an den drei unbehandelten Standorten um200 Individuen gegenüber den sechs behandelten, die Individuenzahl der Linyphiiden allerdings verdoppelte sich. KRAUSE (1987) stellte bei der Anwendung des Herbizides Aniten sowohl im Freiland als auch im Labor eine stark toxische Wirkung auf Spinnen, vor allem auf Lycosiden fest. Da auf BerlinerKulturfeldern vor allem das Herbizid Tribunil verwendet wird, dessen toxische Wirkung auf Spinnen bisher nicht getestet wurde, ist ein Einfluß auf die Spinnen nicht eindeutig auf dieses Mittel zurückzuführen. Die erhöhten Individuenzahlen derLinyphiiden in den nichtbehandelten Halmfruchtfeldern kann auch auf die dort vorhandene hohe Krautschichtdeckung (bis $70 \%$ in Hal9) gegenüber $1 \%$ in den vegetationskundlich untersuchten herbizidbehandelten Äckern zurückgeführt werden.

\section{Dominanzstruktur}

Die Dominanzstruktur der Spinnenzönosen auf den Kulturbiotopen und ihrer ökologisch verwandten Standorte (Brachen, Feldgehölze, Feldpfuhle und Feldränder) stellt sich relativ einheitlich dar (Tab. 5). In nahezu allen Untersuchungsflächen sind die Arten Erigone atra, Erigone dentipalpis und Oedothorax apicatus unter den eudominanten ( $>32 \%$ Individuenanteil) bzw. dominanten Arten (>10\% Individuenanteil) zu finden. Lediglich die Ackerbrache (Bra) und die Hecke (Agr2) weisen ein deutlich anderes Dominanzspektrum auf. Anstelle der genannten Linyphiidenarten rücken die Tetragnathide Pachygnatha degeeri und/oder die Lycosiden Pardosa agrestis und $P$. prativaga an die vordersten Dominanzränge (Tab. 5). In den Kulturfeldern selbst überwiegt vor allem Erigone atra. Sie wird lediglich in $\mathrm{Hal} 2$ und Hal8 von Erigone dentipalpis von ihrem ersten Platz verdrängt. Oedothorax apicatus tritt häufiger an trockenen Standorten auf $(\mathrm{Hal} 3, \mathrm{Hal} 4$, $\mathrm{Hal}$, Bra). An feuchteren wird dagegen Oedothorax fuscus häufiger (Hal5, Hal7, RuR2, vgl. Tab. 5 und Tab.1). Unter den 37 Arten, die mit $>1 \%$ Dominanzan den Standorten nachgewiesen wurden, befinden sich 21 Arten der Linyphiidae (57\%) und 10 Arten der Lycosidae (27\%). Nur sechs Arten stammen aus anderen Familien. In den Feldflächen stellen die ersten drei dominanten Arten (Erigone atra, Erigone dentipalpis und Oedothorax apicatus) zwischen $65 \%$ ( $\mathrm{Hal} 3$ ) und $80 \%$ der Individuen (Hal8), verursachen also eine sehr unausgeglichene Dominanzstruktur (vgl. z. B. Abb. 2). Auch der Feldpfuhl (RuR2) unterscheidet sich nur gering in bezug auf die Abfolge der dominanten Arten und in der Dominanzstaffelung von den Halmfrucht- 
Tab. 5: Überblick über die auf den untersuchten Kulturflächen auftretenden Spinnenarten mit einer Aktivitätsdominanz > $1 \%$. Dominanzangaben in Prozent

\begin{tabular}{|c|c|c|c|c|c|c|c|c|c|c|c|c|c|}
\hline & \multicolumn{13}{|c|}{ FALLENSTANDORTE } \\
\hline Arten & Hal1 & Hal2 & Hal3 & Hal4 & Hal5 & Hal7 & Hal6 & Hals & Hal9 & Hac1 & Bra & Agr2 & RuR2 \\
\hline Erigone atra & 33.3 & 18.2 & 27.3 & 26.1 & 39.6 & 40.3 & 40.6 & 20 & 19.8 & 25.9 & 7.1 & 3.2 & 29.2 \\
\hline Erigone dentipalpis & 28.8 & 28.7 & 26.1 & 23.3 & 22.5 & 25.1 & 24.9 & 31.4 & 12.3 & 18 & 5.4 & 1.8 & 19.1 \\
\hline Oedothorax apicatus & 8.6 & 12.7 & 14.5 & 14.2 & 11.8 & 1.6 & 9 & 26.7 & 19 & 27.7 & 17.7 & & 1.2 \\
\hline Pachygnatha degeeri & 5.8 & 3.6 & 4.1 & 6.5 & & 3.9 & 2.7 & & 2.6 & & 11.9 & 19.5 & \\
\hline Meioneta rurestris & 2.2 & & 3.3 & 6.1 & 3.8 & 1.8 & 3.8 & 5.3 & 1.6 & 5.2 & & & \\
\hline Oedothorax retusus & 1.5 & 6.1 & 5.3 & & 2.7 & 2.5 & 3 & 3 & 11 & & 6.8 & 1.1 & \\
\hline Oedothorax fuscus & & 2.3 & 2.8 & 2.7 & 6.5 & 8.6 & 2.2 & & & 1.2 & 4 & & 16.6 \\
\hline Araeoncus humilis & 1.1 & 4.2 & 2 & 1.6 & 4.3 & 5.3 & 2.8 & 1.3 & 3.5 & 1.6 & & & 2 \\
\hline Pardosa prativaga & & & & & & 1.5 & & & 5.6 & & 3.9 & 15.6 & 3.8 \\
\hline Pardosa agrestis & 3.5 & 5.2 & 1.8 & & & & 2.6 & 4.8 & 1.1 & 1.9 & 14.6 & & \\
\hline Bathyphantes gracilis & & 5.4 & & & 1.7 & 1.7 & 1.1 & & 1.5 & 10 & & 2.3 & 4.8 \\
\hline Pardosa amentata & & & 3.7 & 1.2 & & & 1.4 & & 12.6 & & & 2.3 & \\
\hline Centromerita bicolor & & & & & & & & & & & 5.8 & 2.6 & \\
\hline Erigone longipalpis & & & & 1.2 & & 3.6 & 1.5 & & & & & & 11 \\
\hline Centromerus sylvaticus & & 1.3 & & & & & & & & & & 4.2 & \\
\hline Pardosa palustris & 1.1 & & & & & 1.1 & & 1.7 & & & 12.1 & & \\
\hline Bathyphantes parulus & & & & & & & & & & & & 9 & \\
\hline Trochosa ruricola & & & & & & & & & 3.1 & & & 6.3 & \\
\hline Alopecosa cuneata & & & & & & & & & & & & 5.5 & \\
\hline Pirata piraticus & & & & & & & & & & & & & 3.7 \\
\hline Pachygnatha clercki & & & & & 1.9 & & & & & & 1.3 & & 1.7 \\
\hline Xysticus kochi & & & & & & & & & & & 1.2 & & \\
\hline Dicymbium brevisetosum & & & & & & & & & & & 1.1 & 1.2 & \\
\hline Robertus lividus & 1.4 & & & & & & & & & & & & \\
\hline Stemonyphantes lineatus & 1.2 & & & & & & & & & & & & \\
\hline Trochosa terricola & 1.2 & 1.8 & & & & & & & & & & & \\
\hline Silometopus reussi & & & 2.6 & & & & & & & & & & \\
\hline Diplostyla concolor & & & & & & & & & & & & 3.1 & \\
\hline Pocadicnemis pumila & & & & & & & & & & & & 2.8 & \\
\hline Zora spinimana & & & & & & & & & & & & 1.9 & \\
\hline Alopecosa pulverulenta & & & & & & & & & & & & 1.4 & \\
\hline Troxochrus scabriculus & & & & & & & & & & & & 1.2 & \\
\hline Xysticus cristatus & & & & & & & & & & & & 1.2 & \\
\hline Ceratinella brevis & & & & & & & & & & & & 1 & \\
\hline Xerolycosa miniata & & & & & & & & 1.5 & & & & & \\
\hline Lepthyphantes tenuis & & & & & & & & & 1 & 1.5 & & & \\
\hline Ostearius melanopygius & & & & & & & & & & 2.3 & & & \\
\hline Individuenzahlen & 1148 & 971 & 1230 & 1530 & 3176 & 2536 & 1902 & 1452 & 1761 & 1844 & 7893 & 1869 & 969 \\
\hline
\end{tabular}

feldern (Tab. 5, Abb. 3). Dies ist durch Randeffekte des inn allseitig umgebenden Feldes Hal7 zu erklären. Der nur temporär wasserführende Feldpfuhl kann an seinen schmalen Ufern keine typisch ausgebildete Spinnenzönose beherbergen. Fragmentarisch zeigt sie sich jedoch im häufigeren Auftreten von hygrophilen Arten wie Pirata piraticus, Pachygnatha clercki, Gnathonarium dentatum und Arctosa leopardus.

Lediglich die Ackerbrache (Bra) und die Hecke (Agr2) zeigen eine gleichmäßigere Dominanzstaffelung (Abb. 4 und 5). 


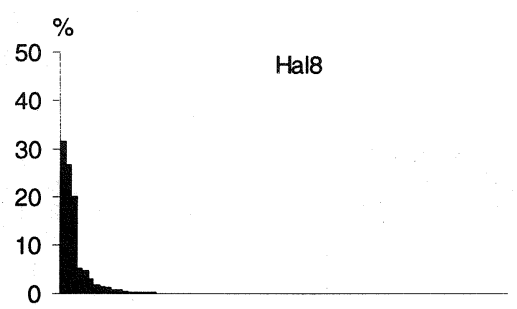

32 Arten, 1452 Individuen

Abb. 2: Dominanzstaffelung der Spinnen am Standort "Hal 8" (Winterroggen Kladow)

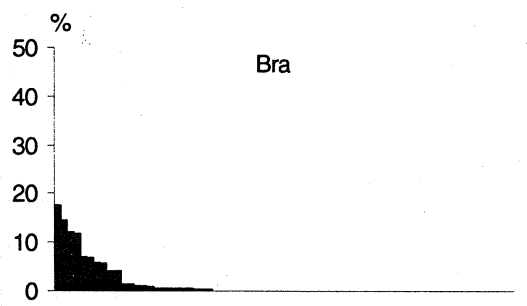

69 Arten, 7893 Individuen

Abb. 4: Dominanzstaffelung der Spinnen am Standort "Bra" (Brachacker Spandau)

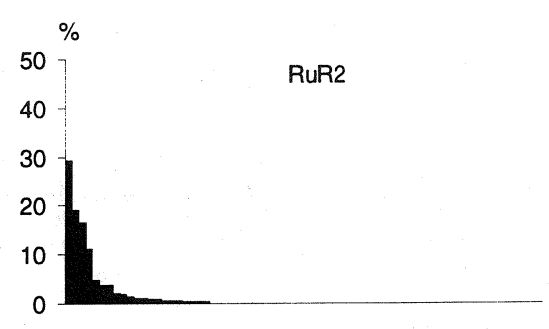

31 Arten, 969 Individuen

Abb. 3: Dominanzstaffelung der Spinnen am Standort "RuR2" (Feldpfuhl Heiligensee)

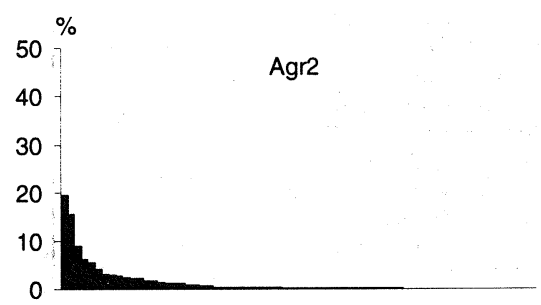

81 Arten, 1869 Individuen

Abb. 5: Dominanzstaffelung der Spinnen am Standort "Agr2" (Feldhecke Lübars)

\section{Größenklassen}

Auf den untersuchten Berliner Kulturstandorten sind weder sehr kleine $(<2 \mathrm{~mm})$ noch sehr große Spinnen ( $>15 \mathrm{~mm}$ ) häufiger vertreten. Den größten Anteil sowohl bei den Arten als auch bei den Individuen stellen kleine bis mittelgroße (2-9,9 mm) Spinnen aus den Familien Linyphiidae und Lycosidae. Betrachtet man die Größenklassenverteilung nach Standortgruppen getrennt, so fällt auf, daß besonders in der Hecke (Agr2, Abb. 6) die Arten- und Individuenanteile der kleinen und mittelgroßen Spinnen nahezu ausgeglichen sind. Dies trifft zwar für die Artenanteile der Standortgruppe "Halmfrucht mit Herbizideinsatz" ebenfalls zu, jedoch sind die Individuenanteile deutlich zugunsten derkleinen Spinnen verschoben (Abb. 7). Auch auf den Getreidefeldern ohne Herbizideinsatz gehören über $80 \%$ der Individuen zu den 


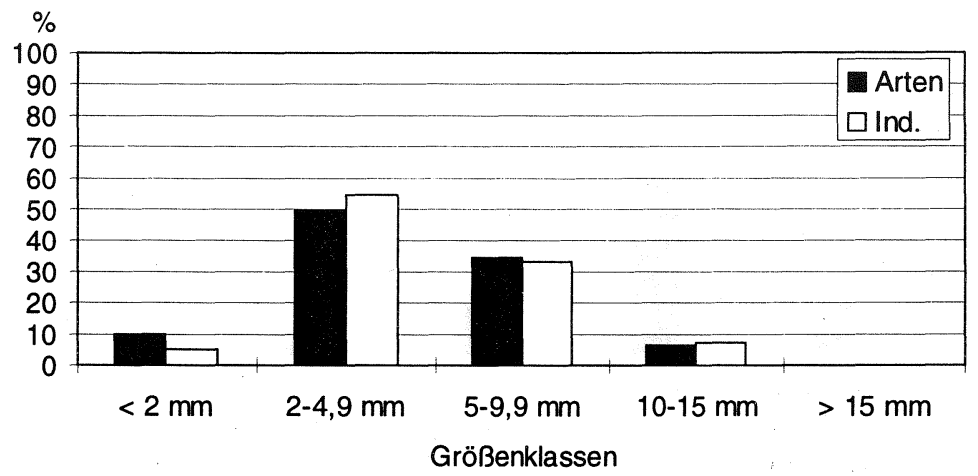

Abb. 6: Verteilung der Arten und Individuen auf die Größenklassen am Standort "Agr2". 81 Arten, 1869 Individuen

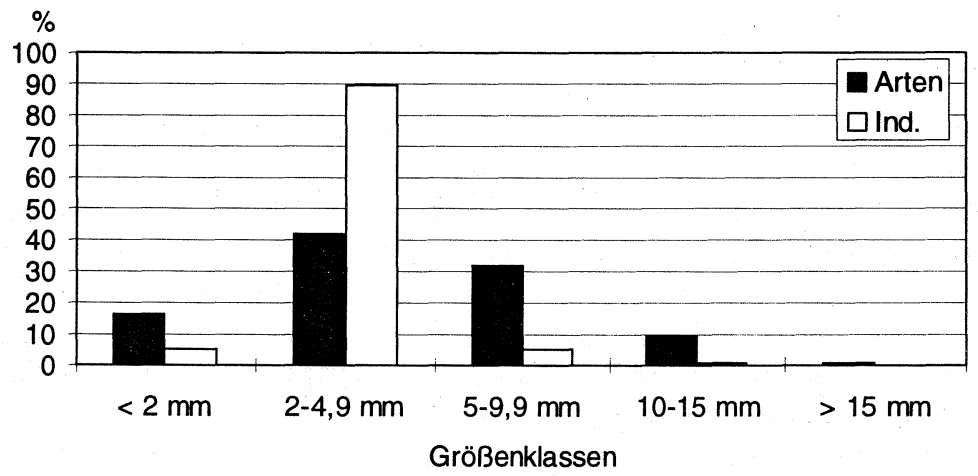

Abb. 7: Verteilung der Arten und Individuen auf die Größenklassen an den Standorten "Halmfrucht mit Herbizideinsatz". 117 Arten, 10591 Individuen

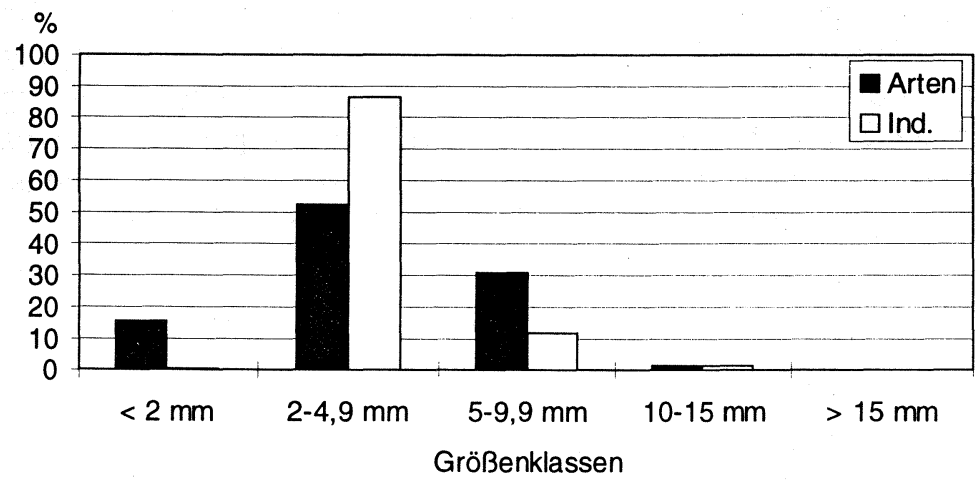

Abb. 8: Verteilung der Arten und Individuen auf die Größenklassen an den Standorten "Halmfrucht ohne Herbizideinsatz". 65 Arten, 5114 Individuen 


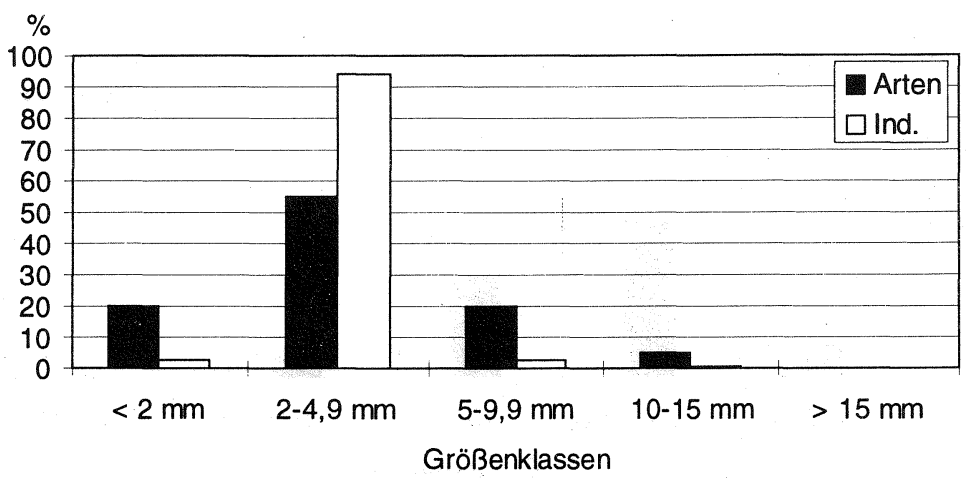

Abb. 9: Verteilung der Arten und Individuen auf die Größenklassen am Standort "Hac1". 40 Arten, 1844 Individuen

kleinen Arten. Im Gegensatz zu der vorherigen Standortgruppe, die den gleichen Artenanteil an mittelgroßen Spinnen besitzt (zu denen vor allem Lycosiden gehören), sind die Individuenanteile auf den herbizidfreien Feldern doppelt so hoch (Abb. 8). Das Extrem der Größenklassenverteilung finden wir auf dem Hackfruchtfeld (Hac1, Abb. 9). Über $50 \%$ der Arten und über $90 \%$ der Individuen stellen die kleinen Spinnen. Der Arten- und Individuenanteil der mittelgroßen Spinnen ist im Vergleich zu den anderen Standortgruppen am geringsten. Bereits HEYDEMANN (1953) stellte fest, daß sich die häufige Bodenbearbeitung auf Hackfruchtfeldern ungünstig auf den Arthropodenbestand auswirkt: "Allein was nützt der geringe Raumwiderstand, den derPflanzenbestand den Tieren bietet, wenn die zahlreichen Eingriffe in die Bodenstruktur, die für die Hackfruchtfelder typisch sind, schon ein so vernichtendes Blutbad gerade unter den nützlichen räuberischen Gliederfüßlern angerichtet haben und überhaupt für eine ungestörte Ausbreitung der Kartoffel-Zönose nur allenfalls 3 Monate zur Verfügung stehen (Juli-September), während doch auf dem Wintergetreidefeld immerhin 9 Monate vergehen, ohne daß die Bodenstruktur auffällig seitens der Menschen verändert wird." (HEYDEMANN 1953, S. 219). 


\section{Die Verteilung der Arten und Individuen auf die ökologischen Typen}

und Pflanzenformationen

Die Verteilung der Arten und Individuen auf die ökologischen Typen (ÖT) und Pflanzenformationen ist ähnlich uniform wie die Dominanzstaffelung. Auf den Halmfruchtfeldern verteilen sich zwischen 30 und $40 \%$ der Arten und 60 bis $80 \%$ der Individuen auf den ökologischen Typ der euryöken Freiflächenarten (eu). Weitere 30 bis $40 \%$ der Arten und zwischen 20 und $40 \%$ der Individuen entfallen auf xerotherme Freiflächenarten (x) (s. z. B. Hal5, Abb. 10). Jenach Feuchtigkeitsverhältnissen und Umgebung derÄckertreten an einigen Standorten noch bis zu 10 (seltener $20 \%$ ) hygrophile Freiflächenarten (h) (Abb. 10) und/oder Waldarten auf. Eine abweichende Verteilung finden wir auf der Brache (Abb. 11), auf der Arten- und Individuenanteile euryöker und xerothermer Freiflächenarten nahezu ausgeglichen sind, in der Hecke, in der der Anteil derWaldarten zusammengenommen über $30 \%$ beträgt (Abb. 12) und am Feldpfuhl (Abb. 13), wo hygrophile Freiflächenarten zu einem Viertel vertreten sind. Die Arten- und Individuenanteile der euryöken Freiflächenarten und der Xerothermen sind dort ähnlich hoch wie auf dem Brachacker (vgl. Abb. 12 mit Abb. 13.).

Die Arten der Äcker (als Ackerarten bezeichne ich im folgenden Arten, die ihr Schwerpunktvorkommen in der Pflanzenformation 14 besitzen bzw. die in der vorliegenden Untersuchung mit deutlicher Bevorzugung in den Äckern auftraten) sind auf den Halmfruchtfeldern auch in ihren Individuenanteilen weitaus am häufigsten (z. B. Hal5, Abb. 14). Nennenswerte Anteile erreichen an einigen Standorten lediglich Trocken- (z. B. an den Standorten $\mathrm{Hal} 1 \mathrm{und} \mathrm{Hal} 3$ ) und Wiesenarten (an den Standorten Hal5 und Hal9, Abb. 14 und 15). Auf dem Hackfruchtfeld Hac1 (Abb. 16) fällt der sehr hohe Individuenanteil der Ackerarten (>90\%) auf. Der Anteil an Ackerarten tritt dagegen auf der Brache, vor allem aber in der Hecke deutlich zurück (Abb. 17). An diesen Standorten zeigt sich eine gleichmäßigere Verteilung der Arten- und Individuenanteile auch auf andere Pflanzenformationen. Am Feldpfuhl RuR2 (Abb. 18) fällt der hohe Individuenanteil an Ackerarten und der erhöhte Anteil von Moor- und Feuchtwiesenarten gegenüber den anderen Standorten auf. 


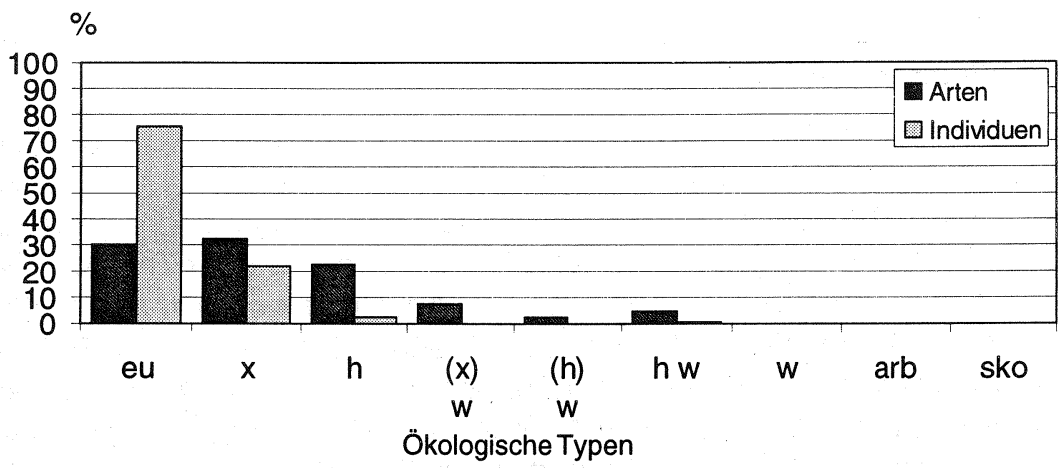

Abb. 10: Verteilung der Arten und Individuen auf die ökologischen Typen am Standort "Hal5". 40 Arten, 3176 Individuen, Abkürzungen s. S. 9-10.

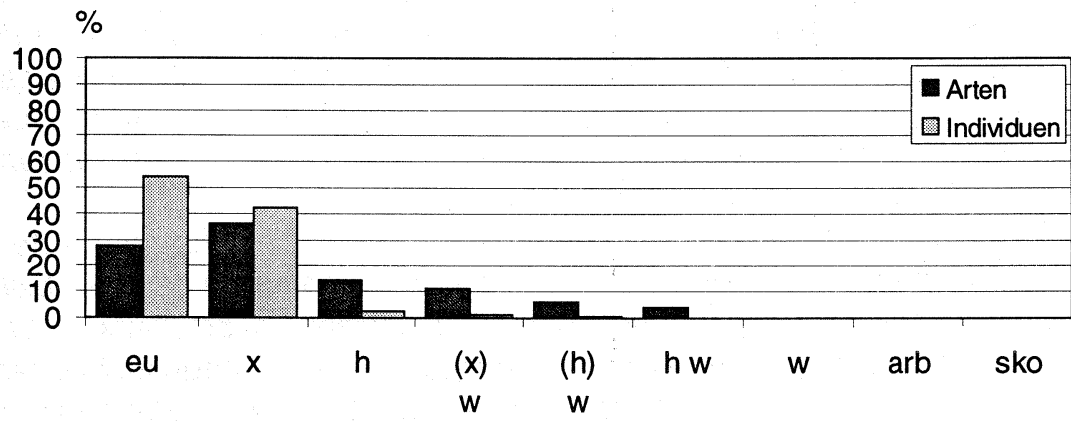

Ökologische Typen

Abb. 11: Verteilung der Arten und Individuen auf die ökologischen Typen am Standort "Bra“. 69 Arten, 7893 Individuen, Abkürzungen s. S. 9-10.

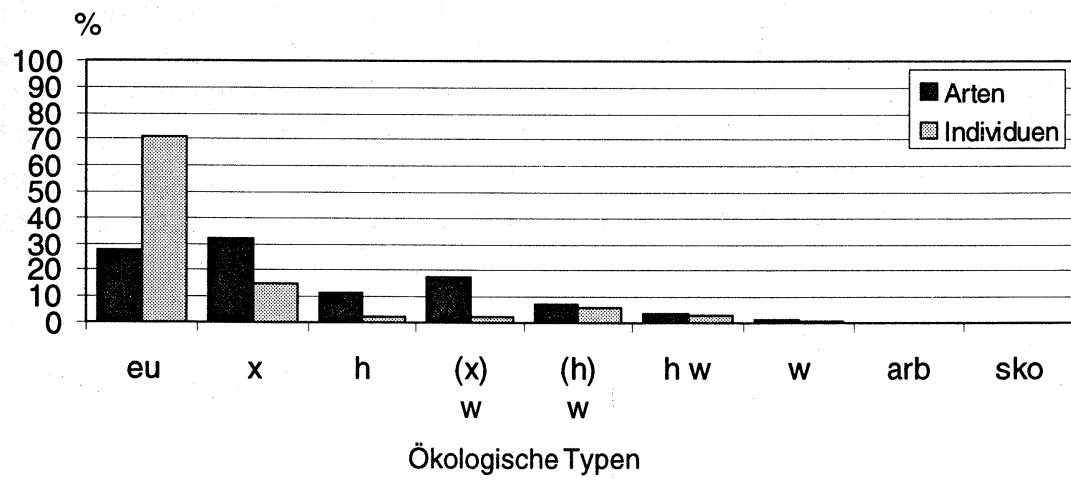

Abb. 12: Verteilung der Arten und Individuen auf die ökologischen Typen am Standort "Agr2". 81 Arten, 1869 Individuen, Abkürzungen s. S. 9-10. 


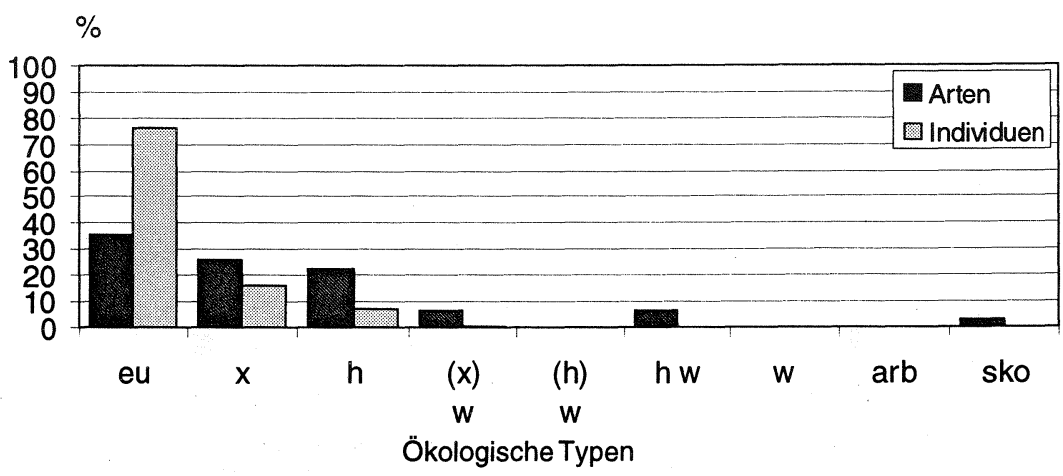

Abb. 13: Verteilung der Arten und Individuen auf die ökologischen Typen am Standort "RuR2". 31 Arten, 969 Individuen, Abkürzungen s. S. 9-10.

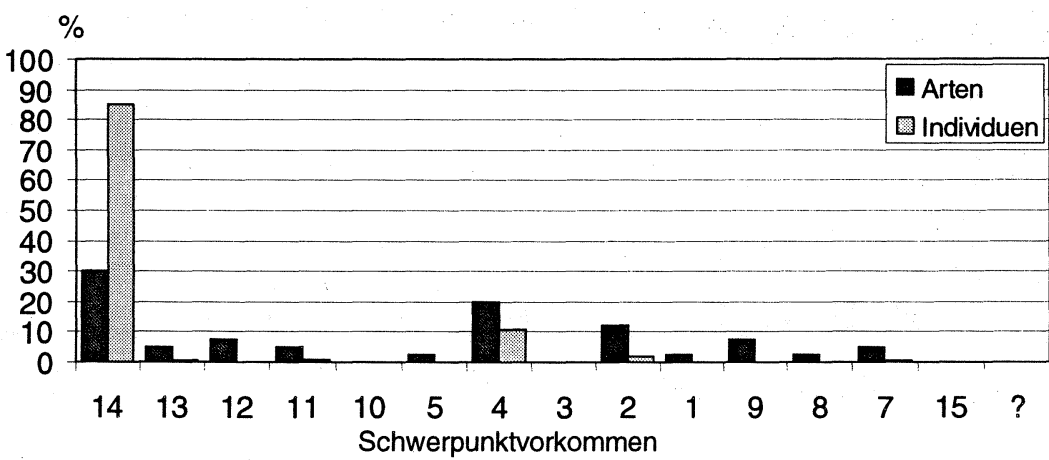

Abb. 14: Verteilung der Arten und Individuen auf die Pflanzenformationen am Standort "Hal5". 40 Arten, 3176 Individuen, Abkürzungen s. S. 11.

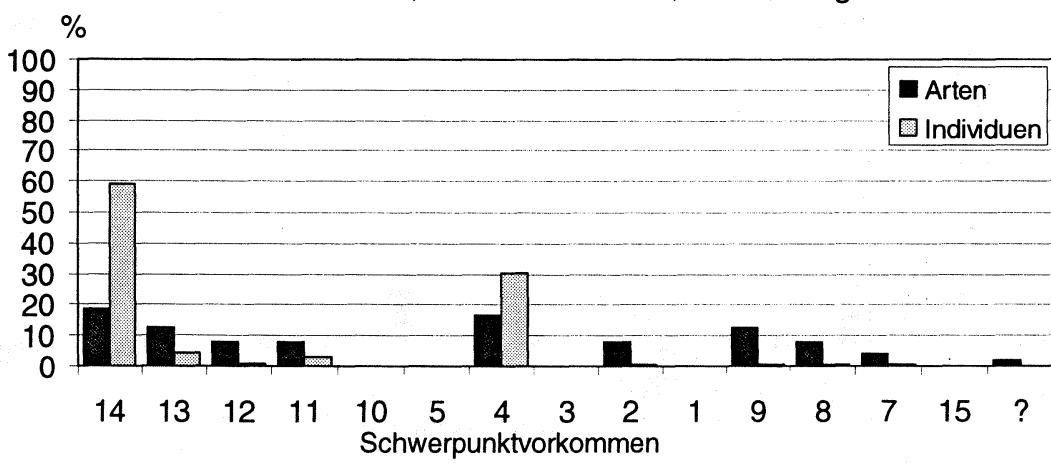

Abb. 15: Verteilung der Arten und Individuen auf die Pflanzenformationen am Standort "Hal9". 48 Arten, 1761 Individuen, Abkürzungen s. S. 11. 


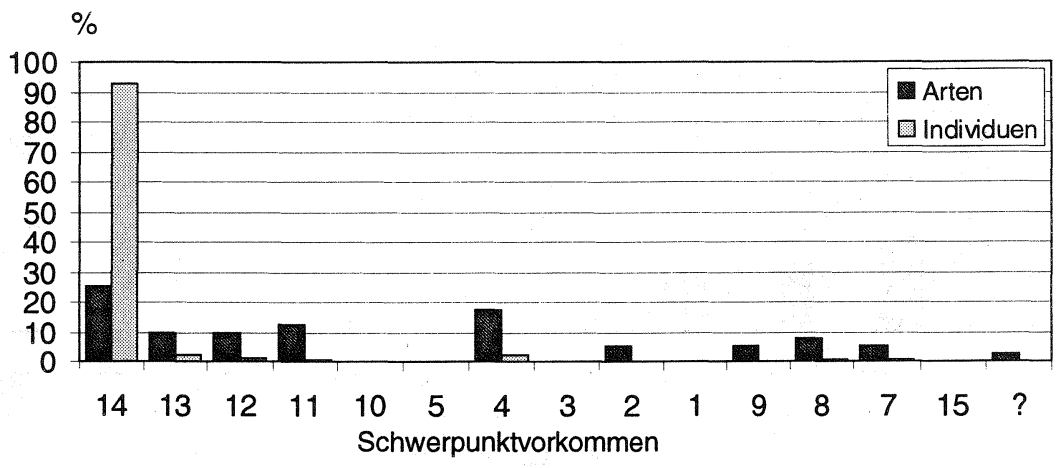

Abb. 16: Verteilung der Arten und Individuen auf die Pflanzenformationen am Standort "Hac1". 40 Arten, 1844 Individuen, Abkürzungen s. S. 11.

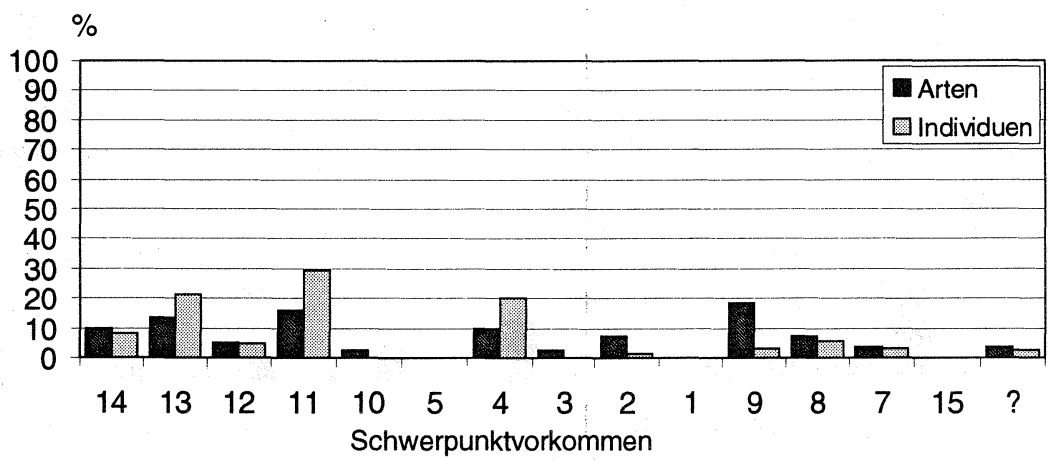

Abb. 17: Verteilung der Arten und Individuen auf die Pflanzenformationen am Standort "Agr2". 81 Arten, 1869 Individuen, Abkürzungen s. S. 11.

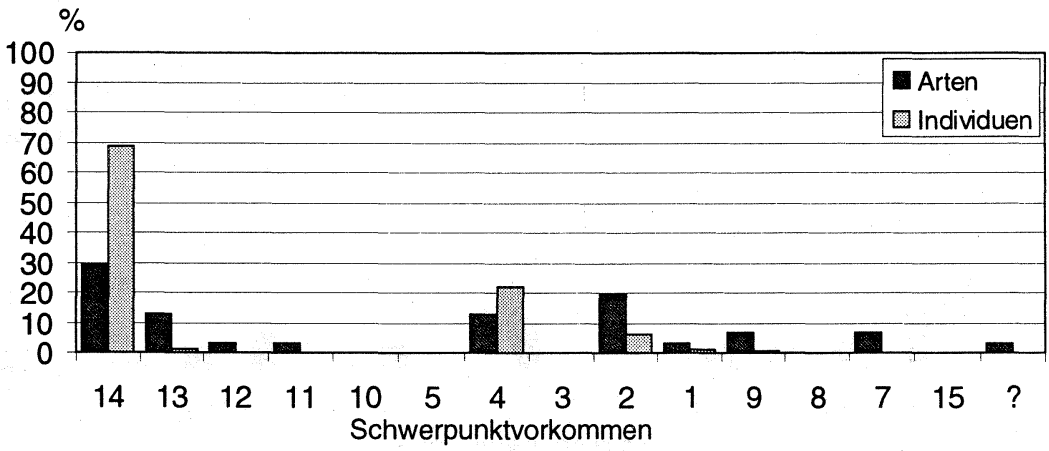

Abb. 18: Verteilung der Arten und Individuen auf die Pflanzenformationen am Standort "RuR2". 31 Arten, 969 Individuen, Abkürzungen s. S. 11. 


\section{Faunistische Ähnlichkeit der Standorte}

Zur Darstellung der faunistischen Ähnlichkeit der Standorte wurde eine Cluster-Analyse auf der Grundlage der Dominanten-Identitäten (RENKONEN 1938) durchgeführt (Abb. 19). Die Verknüpfungslogik bei der Clusterbildung folgt der "unweighted pair group method" (average linkage clustering) (JONGMAN et al. 1987). Die geringste Ähnlichkeit zu allen übrigen Standorten besitzen die Feldhecke (Agr2) mit $20 \%$ und der Brachacker (Bra) mit $30 \%$ Ähnlichkeit. Mit etwas über $50 \%$ folgt der Feldpfuhl (RuR2). Die eigentlichen Acker-Standorte bilden drei Cluster:

Die Lübarser Halmfrucht-Äcker (Hal3 und Hal4) sind mit $80 \%$ Übereinstimmung die ähnlichsten Standorte. Sie liegen unmittelbar benachbart auf der gleichen Feldflur. Ihnen assoziiert sind die Spandauer HalmfruchtStandorte Hal1 und Hal2. Fünf derhäufigsten Arten mit ähnlichen Dominanzwerten sind ihnen gemeinsam (vgl. Tab. 5). Auf allen vier Äckern wird die gleiche Frucht angebaut und das gleiche Herbizid verwendet. Die Krautschicht ist nur spärlich ausgebildet (vgl. Tab. 3). Der Wassergehalt des Bodens war zum Zeitpunkt der Messung auf den Lübarser etwas geringer als auf den Spandauer Feldern. Dies bleibt wahrscheinlich das ganze Jahr über so, denn der Anteil der xerothermen Arten beträgt auf den Spandauer Feldern nur $35 \%$, auf den Lübarser Feldern dagegen über $40 \%$. Da die Fallen relativ nahe am Rand der Felder standen, müssen auch Randeffekte für Unterschiede in der Artenzusammensetzung beider Standortgruppen herangezogen werden. Die Spandauer Felder grenzen unmittelbar an ausgedehnte Forste, die allenfalls durch Sandwege von den Feldern getrennt sind. Es treten hier eine Reihe von Waldarten mit einem Anteil von bis zu $30 \%$ auf, die nur hier auch mit einem nennenswerten Individuenanteil vertreten sind, z.B. Trochosa terricola, Robertus lividus und Centromerus sylvaticus (vgl. Tab. 5). An den Lübarser Standorten dagegen wurden insgesamt nur $15 \%$ Waldarten gefunden. Diese Felder werden von offenem Weideland, einem Grenzstreifen, von Alleen und der Feldhecke Agr2 begrenzt.

Ein weiteres Cluster bilden die Kladower/Gatower Felder Hal8 und Hac1 sowie innen assoziiert Hal9 (Abb. 19). An den Standorten Hal8 und Hal9 wurde zum Untersuchungszeitpunkt Winter-Roggen angebaut, der auf dem Kartoffelacker Hac1 Vorfrucht war. Allen drei Feldern ist gemeinsam, daß sie nicht mit Herbiziden behandelt werden und daher eine ausgeprägte und dichte Krautschicht besitzen (vgl. Tab. 3). Die Standorte Hal8 und Hac1 sind benachbart, stimmen in sechs der häufigsten Arten mit einem hohen Individuenanteil überein (Tab.5) und unterscheiden sich trotz unterschiedlicher Anbaufrucht von dem ca. 3 km entfernten Winter-Roggen-Standort Hal 9. 
Hier zeigt sich wiederum die räumliche Nähe von Standorten als größerer Einfluß auf die Arten- und Individuenzusammensetzung als unterschiedliche abiotische (Feuchte, Licht) und biotische Faktoren (Anbaufrucht).

Das dritte Cluster schließlich wird von den Standorten $\mathrm{Hal} 5$ und $\mathrm{Hal} 7 \mathrm{Hnd}$ innen assoziiert Hal 6, also den Marienfelderund HeiligenseerFeldstandorten, gebildet. Sie unterscheiden sich stark in derFeuchtigkeit, wobei der Standort Hal6 zum Zeitpunkt derMessung dernasseste war(Tab. 1). Trotzdembesitzt dieser nicht den höchsten Anteil an Hygrophilen sondern mit knapp $30 \%$ einen der höchsten Waldartenanteile. Während am Standort Hal5 und besonders intensiv an Hal7 Herbizide gespritzt wurden, blieb Hal6 unbehandelt. Alle drei Standorte haben acht der häufigsten Arten gemeinsam (Tab. 5). Der Hal5 und Hal7 assoziierte Standort Hal6 besitzt zu diesen noch eine faunistischeÄhnlichkeit von $70 \%$, während sie mit einem der anderen beiden Cluster nur knapp $55 \%$ beträgt (Abb. 19).

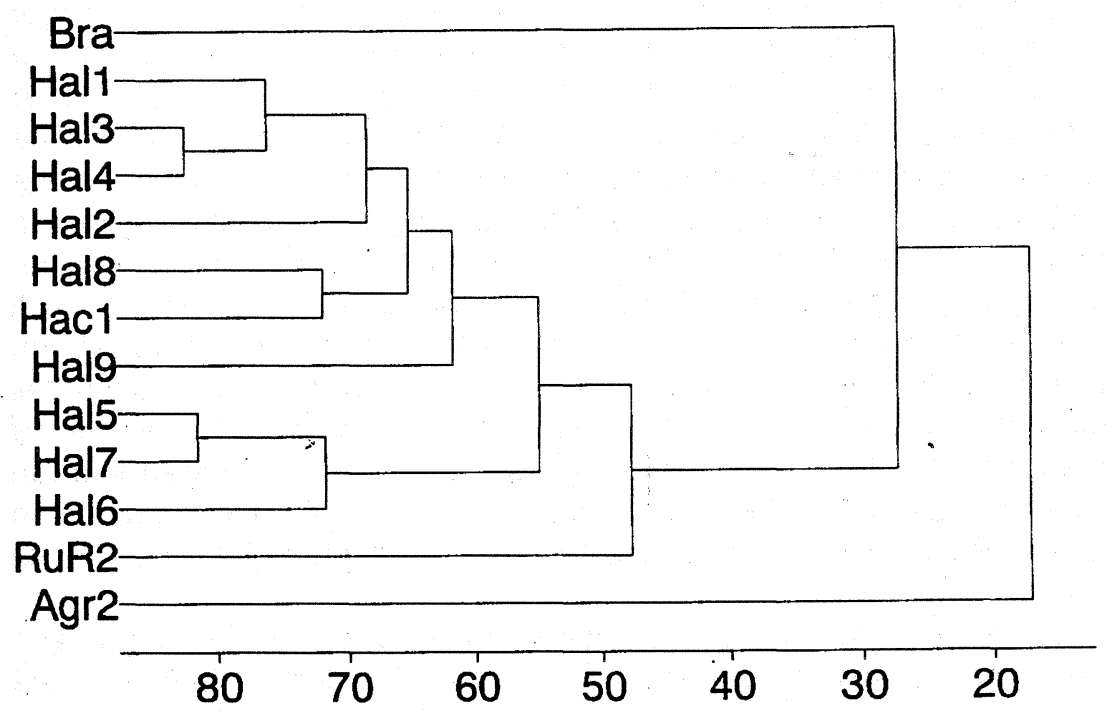

Abb. 19: Faunistische Ähnlichkeiten (in Prozent) der untersuchten Standorte in Berlin, dargestellt als Clusterdiagramm auf der Basis der Dominantenidentitäten nach RENKONEN (1938). 


\section{Welche Faktoren bestimmen die Verteilung der Spinnen auf den Berliner Kulturbiotopen?}

MitHilfe einer multivariaten Analyse derDaten läßtsich auf formalstatistischer Basis beschreiben, welche der gemessenen abiotischen Faktoren die Verteilung der Arten am besten erklären. Dazu wurden die sechs Faktoren Temperatur, Licht, Bodenfeuchte, $\mathrm{pH}$-Wert, organischer Anteil des Bodens und Porenvolumen gemeinsam mit den Individuenzahlen der Spinnenarten einer Kanonischen Korrespondenzanalyse (CCA) nach JONGMAN et al. (1987) unterzogen. Die Individuenzahlen wurden zunächst einer Logarithmustransformation (In ay $+c$, für $a, c=1$ ) unterzogen, damit die häufigsten

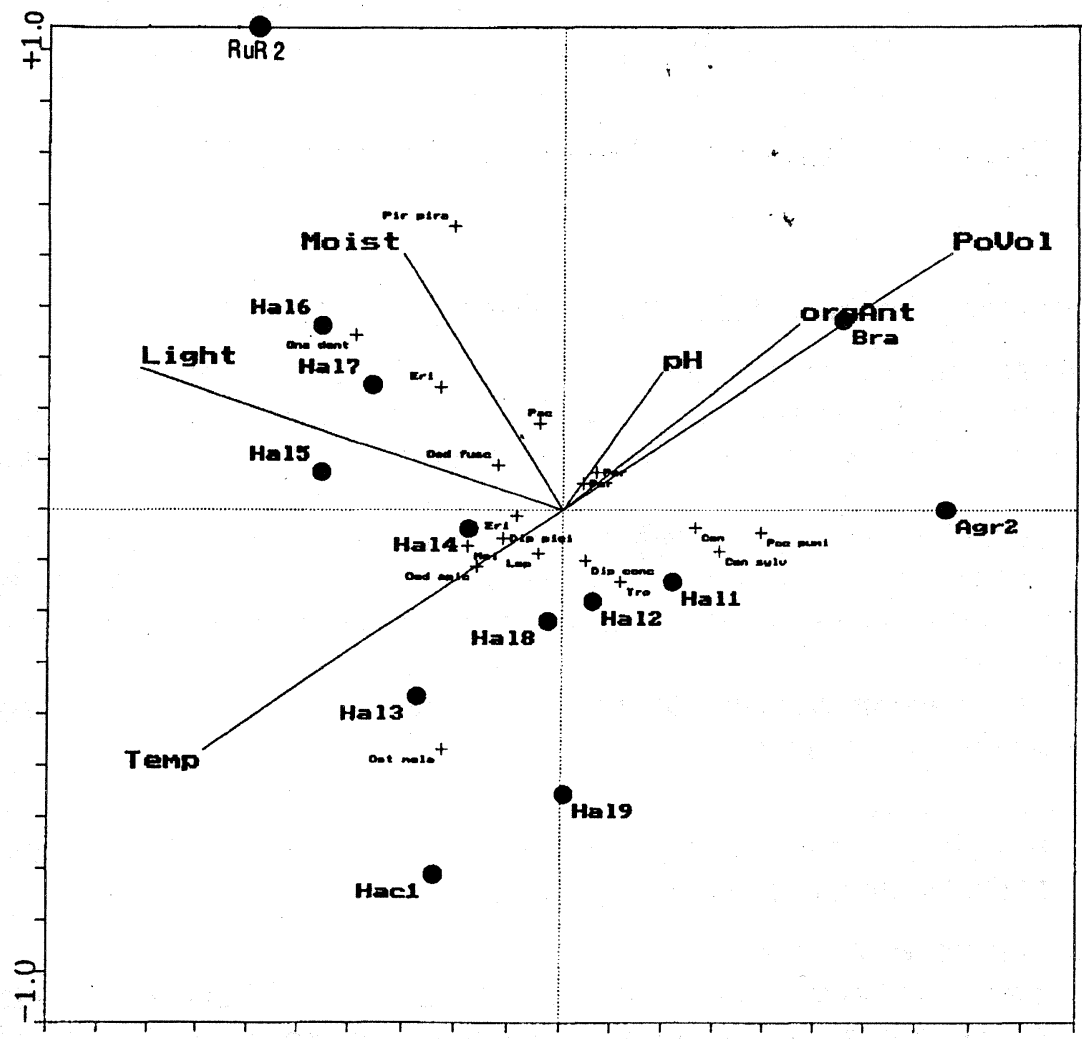

Abb. 20: Ordinationsdiagramm für die Spinnenarten auf der Grundlage einer Kanonischen Korrespondenz-Analyse. Horizontal: 1. CCA-Achse, Vertikal: 2. CCA-Achse. Die vollständigen Artnamen sind der Tab. $4 \mathrm{zu}$ entnehmen 
Arten nicht das Analyseergebnis bestimmen. Um zufällig gefangenen und standortfremden Arten kein zu großes Gewichtbeizumessen, wurden Arten mit einer Dominanz $<1 \%$ an allen Standorten nicht mit in die Analyse einbezogen. Die Ergebnisse wurden als sog. Triplot (Standorte, Arten und abiotische Faktoren) in einem zweidimensionalen Ordinationsdiagramm dargestellt (Abb. 20). Keine der Faktoren ist besonders hoch mit einer der CCA-Achsen korreliert, da die Summe der Varianz aller vier CCA-Achsen lediglich 0,31 beträgt. Dies bedeutet, daß die gemessenen abiotischen Parameter die Verteilung der Spinnen an den Berliner KulturflächenStandorten nicht erklären können. Anders ausgedrückt: Die Spinnenzönosen der Äcker bestehen vor allem aus eurytopen Freiflächenarten, die an einigen Standorten z.T. in sehr hohen Individuenzahlen nachgewiesen wurden. Die Abb. 10 bis 13 zeigen auch, daß an einigen Standorten bis zu $90 \%$ der Individuen von diesem ökologischen Typ gestellt werden.

\section{DISKUSSION}

\section{Spinnenzönosen mitteleuropäischer Kulturfelder}

Im nächsten Schritt soll analysiert werden, ob die für die Berliner Standorte gefundenen Ergebnisse auch für mitteleuropäische Kulturbiotope insgesamt gelten und aus welchen naturnahen Lebensräumen ihre Spinnenzönosen stammen.

Nach Auswertung eigener Ergebnisse sowie von Arbeiten aus Finnland bis in die Schweiz einerseits und Belgien bis nach Polen andereseits, werden charakteristische Spinnenzönosen für Kulturbiotope in Mitteleuropa formuliert.

Ausgewertet wurden Standorte mit folgenden Anbaufrüchten bzw. folgende Kulturbiope $(n=17)$ :

Ackerstandorte:

Kartoffeln, Kohl, Winterroggen, Hafer, Zuckerrüben, Winterweizen, Mais, Hopfen, Luzerne, Klee und Obst.

Kulturbiotope (allgemein):

Halmfruchtfelder, Hackfruchtfelder, Ackerbrachen, Feldränder, Feldpfuhle, Wiesen und Weiden (nur als Vergleichsstandorte in Zusammenhang mit Arbeiten über die vorher genannten Kulturbiotope). 
In den im folgenden aufgeführten Gruppen sind nur solche Arten enthalten, die an den Untersuchungsstandorten bei quantitativen Untersuchungen mit einer Dominanz 1\% auftraten bzw. bei qualitativen Untersuchungen als "sehr häufig" oder "häufig" bezeichnet wurden.

Die erste Gruppe umfaßt agrobionte bzw. agrophile Spinnen. Dies sind Arten, die in nahezu allen Kulturbiotopen, zumindest jedoch in allen Kulturfeldern auftraten. Sie entsprechen der Gruppe I bei LUCZAK (1979) und sind in Kulturbiotopen stets häufiger als in naturnahen Lebensräumen:

Erigone atra, E. dentipalpis, Meioneta rurestris, Oedothorax apicatus, Pachygnatha degeeri und Pardosa agrestis.

Es werden in dieser Kategorie weniger Arten genannt als bei LUCZAK (1979). Sie zählte noch Trochosa ruricola und Aculepeira ceropegia dazu. Erstere ist nach der vorliegenden Auswertung im Acker eher seltener und tritt sowohl in nassen wie auch in trockneren offenen Flächen aller Art häufiger als in Äckern auf, letztere kann nur im Osten des Gebietes als typische Art der Kulturfelder angesehen werden.

In derfolgenden Gruppe sind Arten aufgeführt, die im Vergleich der zur Auswertung herangezogenen Standorte in mehrals $50 \%$ der Ackerstandorte (9) nachgewiesen wurden. (Gruppe II nach LUCZAK 1979):

Araeoncus humilis, Bathyphantes gracilis, Dicymbium brevisetosum,

Oedothorax fuscus, Pardosa palustris und $P$. pullata.

Es sind solche Arten, die in naturnahen Biotopen häufiger auftreten, aber dennoch in Agrozönosen dominant sind. Zu ihnen gehören meist eurytope Freiflächenarten. Eine Ausnahme ist Pardosa pullata, die als Feuchtezeiger für nasse Kulturbiotope gelten kann. LUCZAK (1979) führt in dieser Gruppe weiterhin Arten auf, die auf Pflanzen leben bzw. die Netzbauer sind, unter innen Theridiiden, Philodromiden und Araneiden. Da in den meisten der ausgewerteten Arbeiten jedoch bevorzugt die epigäischen Spinnen erfaßt wurden, bleiben diese Arten hier aus methodischen Gründen unberücksichtigt, obwohl sie teilweise nach NYFFELER (1982) quantitativ wichtige Prädatoren in Getreidefeldern darstellen. Nach RAATIKAINEN \& HUHTA (1968) haben Arten dieser Gruppe inr Schwerpunktvorkommen an unbewaldeten Standorten, Wäldern, Ökotonen sowie Gewässerrändern.

Arten, die an 25 bis $50 \%$ der Ackerstandorte auftraten (4-8), wurden in der Gruppe III zusammengefaßt. Nach LUCZAK (1979) können sie auf Feldern regelmäßig beobachtet werden, sind meist jedoch in nur geringer Häufigkeit vorhanden (Ausnahme: Lycosidae). Angrenzende, naturnahe 
Habitate sind ihre bevorzugten Lebensräume. Sie besiedeln Agrarbiotope nur in geringem $\mathrm{Maße}$ odersporadisch, eine dauerhafte Besiedlung geschieht unter den für diese Arten suboptimalen Bedingungen im Allgemeinen nicht. Arten dieser Gruppe sind:

Centromerita bicolor, Lepthyphantes tenuis, Mangora acalypha, Microlinyphia pusilla, Pardosa amentata, Porrhomma pygmaeum/ $P$. microphthalmum (diese beiden Arten wurden in der älteren Literatur möglicherweise nicht immer unterschieden), Tetragnatha pinicola, Trochosa terricola, Xysticus cristatus und $X$. kochi.

Weiterhin umfaßt diese Gruppe auch Arten, die als Feuchte- oder Trockenheitszeiger gelten.

Differentialarten für nasse Standorte:

Diplostyla concolor, Pachygnatha clercki, Pardosa prativaga und Pirata piraticus. Die von innen bevorzugt besiedelten Äcker besitzen lehmige Böden.

Differentialarten für trockene Standorte:

Arctosa perita, Pelecopsis parallela und Xerolycosa miniata. Diese Arten leben bevorzugt auf Sandäckern, wobei sie mit Ausnahme von Arctosa perita nur auf Hackfruchtfeldern auftreten.

\section{a) Die Spinnenzönosen der Wiesen und Weiden}

Um herauszuarbeiten, ob sich Spinnenzönosen anderer Kulturbiotope von Ackerzönosen imengeren Sinne unterscheiden, werden ihre Artenbestände verglichen und Gemeinsamkeiten aufgeführt.

Folgende Arten der Wiesen und Weiden treten auch regelmäßig in Ackerstandorten auf:

Alopecosa pulverulenta, Araeoncus humilis, Bathyphantes gracilis, Centromerita bicolor, Dicymbium brevisetosum, Diplocephalus cristatus, Erigone atra, E. dentipalpis, Lepthyphantes tenuis, Meioneta rurestris, Oedothorax apicatus, Oe. fuscus, Oe. retusus, Pachygnatha clercki, $P$. degeeri, Pardosa agrestis, $P$. amentata, $P$. prativaga, $P$. palustris, $P$. pullata, Trochosa ruricola, Xysticus cristatus und $X$. kochi.

Folgende Arten sind dagegen für Wiesen- und Weiden-Standorte charakteristisch:

Allomengea vidua, Alopecosa cuneata, Arctosa leopardus, Oedothorax gibbosus, Ozyptila trux, Pirata hygrophilus, $P$. piraticus, Tallusia experta, Trochosa spinipalpis und Xysticus bifasciatus. 
Die Spinnenzönosen der Wiesen und Weiden sind damit denen der Äcker sehrähnlich. Dabei ist erstere Zönose sehrheterogen. Aus ihr rekrutiert sich wahrscheinlich sowohl der hygrophile als auch der xerophile Anteil der Ackerzönosen. Insgesamt gesehen gibt es nur eine geringe Anzahl exclusiver Wiesen- und Weidenarten. Alle diese Arten können auch in naturnahen Biotopen vorkommen: in eutrophen und oligotrophen Verlandungsgesellschaften, Kriechpflanzenrasen, hygrophilen Therophytenfluren, Halbtrocken- und Sandtrockenrasen, etc.

Als Differentialarten für nasse Wiesen gelten:

Allomengea vidua, Arctosa leopardus, Oedothorax gibbosus, Ozyptila trux, Pachygnatha clercki, Pardosa prativaga, Pirata hygrophilus, $P$. piraticus und Trochosa spinipalpis.

Differentialarten für trockene Wiesen und Weiden:

Alopecosa cuneata, Xysticus cristatus und X. kochi.

\section{b) Die Spinnenzönosen der Hecken}

Hecken sind unmittelbar an die Kulturlandschaft angrenzende Biotope, die sich jedoch in der Artenzusammensetzung stark von den angrenzenden Feldern unterscheiden. Feldarten dringen kurzfristig ein, sie scheinen jedoch nach neueren Untersuchungen (BLICK 1988) bei der Wiederbesiedelung von Ackerstandorten im Frühjahr, nach dem Umpflügen oder nach der Mahd nur eine äußerst geringe Rolle zu spielen.

Neben den auch in Kulturbiotopen vorkommenden Arten

Bathyphantes gracilis, Dicymbium brevisetosum, Diplostyla concolor, Erigone atra, E. dentipalpis, Meioneta rurestris, Oedothorax apicatus, Pachygnatha degeeri, Pardosa palustris, P. pullata und Trochosa ruricola

treten folgende (Wald-) Arten exclusiv in der Hecke auf:

Ceratinella brevis, Clubiona comta, Coelotes terrestris, Diplocephalus latifrons, D. picinus, Lepthyphantes tenebricola, L. zimmermanni, Maso sundevalli, Micrargus herbigradus, Microneta viaria, Ozyptila praticola, Pachygnatha listeri, Paidiscura pallens und Robertus lividus.

In der Hecke kommen sowohl laufaktive (Lycosiden) und schattentolerante Arten (Bathyphantes gracilis, Diplostyla concolorund Pachygnatha degeeri) der angrenzenden Kulturbiotope als auch ausgesprochene Waldarten vor, die im Vergleich zu den offenen Kulturbiotopen als exclusiv für die Hecke 
gelten können. Dies bestätigt die Aussage von TISCHLER $(1950,1980)$, daß Hecken doppelte Waldränder, also Ökotone sind und die von ROTTER \& KNEITZ (1977), daß Hecken Waldrefugien in der Agrarlandschaft darstellen.

\section{c) Die Spinnenzönosen der Feldränder}

Mehr noch als die Hecken sind die Feldränder durch die Fauna der Kulturflächen beeinflußt, da keine so großen Unterschiede in der Ausprägung der abiotischen Verhältnisse vorhanden sind wie zwischen Acker und Hecke. Daher ist auch der Anteil der Feldarten in den angrenzenden Rändern sehr hoch:

Araeoncus humilis, Bathyphantes gracilis, Centromerita bicolor, Dicymbium brevisetosum, Diplostyla concolor, Erigone atra, E. dentipalpis, Lepthyphantes tenuis, Meioneta rurestris, Oedothorax apicatus, Oe. fuscus, Pachygnatha clercki, P. degeeri, Pardosa amentata, P. palustris, P. pullata, Pelecopsis parallela und Trochosa ruricola.

Arten der Feldränder, die auch in Hecken vorkommen:

Clubiona comta, Diplocephalus latifrons und $D$. picinus.

Weiter treten auch einige Arten der Wiesen und Weiden in Feldrändern auf: Alopecosa pulverulenta, Bathyphantes parvulus, Diplocephalus cristatus, Pardosa prativaga, Pirata piraticus, Stemonyphantes lineatus (fast exclusiv im Feldrand) und Troxochrus scabriculus.

Durch intensiven Kontakt mit der Kulturfläche sowie durch ähnliche Vegetationsstruktur besitzen Feldränder nahezu keine exclusiven Arten. Die Anzahl der in ihnen vorhandenen Ackerarten ist deutlich höher als in der Hecke, was auf ähnlich ausgeprägte abiotische Faktoren (da gehölzfrei) zurückgeführt werden kann. Mit wenigen Ausnahmen (Diplocephalus latifrons, D. picinus und Maso sundevalli) kommen im Feldrand keine Waldarten vor. Dagegen gibt es zahlreiche Arten der Wiesen und Weiden. Der Feldrand beherbergt daher eine angereicherte Ackerfauna. 


\section{d) Die Spinnenzönosen der Ackerbrachen}

Brachen werden überwiegend durch Arten charakterisiert, die ein Schwerpunkt- und/oder ein Hauptvorkommen in Äckern besitzen ( $v g l$. PLATEN et al. 1991):

Araeoncus humilis, Bathyphantes gracilis, Centromerita bicolor, Dicymbium brevisetosum, Erigone atra, E. dentipalpis, Mangora acalypha, Meioneta rurestris, Microlinyphia pusilla, Oedothoraxapicatus, Oe. fuscus, Pachygnatha clercki, P. degeeri, Pardosa agrestis, $P$. palustris, $P$. prativaga, $P$. pullata, Trochosa ruricola, Troxochrus scabriculus und Xysticus kochi.

Nur zwei Arten besitzen sie mit den Wiesen zusammen:

Oedothorax retusus und Xysticus cristatus.

Exclusive Arten der Ackerbrachen gibt es nicht. Die Brachen zeigen alle Eigenschaften eines typischen Ackers, wenn sie nicht zu lange brach gelegen haben. In jungen Brachen treten nur sehr vereinzelt Wiesenarten und Arten der Feldränder auf. Brachen sind daher zwar arten- und individuenreicher (vor allem an Wolfspinnen) als Äcker, jedoch ist der Anteil der Wiesenarten geringer als in Feldrändern. Letztere sind die vergleichsweise stabileren Biotope, da sie längere Zeit ungestört sind. Kurze Zeit nach Aufgabe der Ackernutzung können sich auf den Brachen keine stabilen Zönosen ausbilden. Hecken- und Waldarten fehlen weitgehend. Eine Ausnahme stellen einige subrezedente Arten dar, deren Auftreten durch Randeffekte angrenzender Wälder interpretiert werden können.

\section{e) Die Spinnenzönose des Feldpfuhls}

Der untersuchte Feldpfuhl steht in intensivem Kontakt zur Agrarfläche selbst. Es ist daher anzunehmen, daß die Zönose ebenfalls vor allem aus Ackerarten zusammengesetzt ist. Allerdings ist hier die starke Abweichung zumindest eines abiotischen Faktors im Vergleich zu den Ackerstandorten zu verzeichnen: der Feuchtigkeit. Daher sind vor allem Feuchtezeiger aus anderen Biotoptypen zu erwarten.

Arten, die zur Feldflur gerechnet werden:

Araeoncus humilis, Bathyphantes gracilis, Erigone atra, E. dentipalpis, Meioneta rurestris, Oedothorax apicatus, Oe. fuscus, Pachygntha clercki, Pardosa agrestis, P. palustris und $P$. prativaga. 
Weiterhin treten folgende Arten der Wiesen und Gewässerränder auf:

Bathyphantes parvulus (Feldrand), Gnathonarium dentatum (Gewässerränder), Oedothorax retusus und Pirata piraticus (Wiesen).

Der Feldpfuhl zeigt in bezug auf die Spinnenzönose im wesentlichen alle Merkmale des Ackers, in dem er sich befindet. Ähnlich wie in der Brache überwiegen Ackerarten. Als typische Nässezeiger und Arten von Gewässerrändern treten darüberhinaus Arctosa leopardus, Gnathonarium dentatum, Gongylidiellum murcidum, Pirata piraticus und Trochosa spinipalpis auf.

Der Feld pfuhl zeichnet sich damit im Gegensatz zur Ackerbrache durch eine Anzahl ihm eigener Arten aus.

Zusammenfassend kann gesagt werden, daß die Vergesellschaftung der eudominanten (32-100\%) und der meisten dominanten (10-31,9\%) Arten (dies trifft auf alle Arten der Gruppe I zu) auf mitteleuropäischen Kulturstandorten sehr einheitlich ist. Soweit dies trotz der unterschiedlichen Anzahl von untersuchten Standorten bisher beurteilt werden kann, gilt dies unabhängig von der Anbaufrucht und den abiotischen Standortbedingungen. Die Arten fehlen auch im hohen Norden (Finnland), im Süden (Schweiz), Westen (Belgien) und Osten (Polen) nicht, nur wenige treten als typische Ackerbewohner in den Ländern am Rande des Gebietes neu hinzu. Arten, die mit 1-10\% Dominanz in den Kulturfeldern auftreten, das entspricht den Arten der Kategorien II und III, zeigen dagegen einen viel größeren Dominanzwechsel in Abhängigkeit von der geographischen Lage, den Standortbedingungen und der Art der Anbaufrüchte, was in Einklang mit der Aussage von L.UCZAK (1979) steht. Die Arten der Gruppe III besitzen die geringste, Arten der Gruppe I die stärkste Bindung an Kulturbiotope. Dennoch bezweifele ich, daß es, wie von TISCHLER (1965) und LUCZAK (1979) postuliert, ausschließliche Ackerarten unterden Spinnen gibt: AuchPardosa agrestis ist nicht exclusiv auf Äckern zu finden. Sie lebt ebenso in einer Reihe unterschiedlicher Trockenbiotope wie auch in oberflächlich abgetrockneten Mooren (PLATEN 1989). Wie die Ergebnisse der Kanonischen Korrespondenz-Analyse zeigen, korreliert die Verteilung der häufigsten Arten der Kulturbiotope mit keinem der gemessenen Umweltparameter an den Kulturstandorten in Berlin besonders hoch. Das bedeutet, daß die Zönosen aus euryöken Freiflächenarten zusammengesetzt sind, die durch ihre erfolgreiche Ausbreitungsstrategie (die meisten Arten sind wohl auch als adulte Tiere Fadenflieger), ihre eurychrone Aktivitätszeit im Jahresverlauf ( $41=26,5 \%$ der insgesamt 155 in dieser Untersuchung gefangenen sowie $6=86 \%$ der 7 agrobionten/-philen Arten besitzt eine Aktivitätszeit > 3 Monate) 
sowie ihre hohen Individuenzahlen bieten ihnen bei den vielfältigen Störungen in der Agrobiozönose einen erheblichen Konkurrenzvorteil gegenüber den Arten, die enger eingenischt sind. Auf ihre hohe Ausbreitungskapazität als Fadenflieger ist wohl auch ihre Präsenz sowohl in den verschiedensten Kulturbiotoptypen als auch im gesamten mitteleuropäischen Areal zurückzuführen.

\section{Aus welchen naturnahen Habitaten stammen die Spinnenarten der Kulturfelder und wie werden sie besiedelt?}

Seit HEYDEMANN (1953) und TISCHLER (1965) gilt die für Wirbellose mehr oder weniger anerkannte These, daß sich die Fauna der Äcker aus angrenzenden natürlichen Biotoptypen wie Wäldern, ungenutzten Wiesen und dem Litoral rekrutiert.

TISCHLER (1965) sowie RAATIKAINEN \& HUHTA (1968) fokussieren auf die Herkunft vieler Wirbelloser unter den Ackerarten aus dem Litoral, wobei sie im speziellen Fluß- und Meeresufer, Salzmarschen, Torfmoore und nasse Wiesen meinen. Als Beispiel für solche Arten führt LUCZAK (1979) Tetragnatha extensa, Singa hamata, Xysticus ulmiund Pachygnatha clerckian (weitere Arten siehe vorangegangenes Kapitel). Diese Arten sind jedoch keine allgemein verbreiteten Ackerarten, sondern sie stellen Differentialarten nasser Standorte dar. Sie sind keine euryöken, sondern ausschließlich hygrophile Freiflächenbewohner, die durch ihr Vorkommen im Litoral an Störungen in der Feldflur präadaptiert sind.

Ackerarten, die als Differentialarten für trockene Äcker aufgeführt werden, stammen aus Trockenrasen- und Halbtrockenrasen-Gesellschaften, die als natürliche Habitate lediglich kleinflächig auf exponierten Felsstandorten oder aus neu entstandenen Freiflächen durch Waldbrand entstanden sind. Diese Arten sind aufgrund ihrer Stenökie auch nicht an allen Ackerstandorten vorhanden.

Eine weitere Gruppe von Ackerspinnen wandert nach BONESS (1953) und TISCHLER (1965) aus benachbarten Wäldern ein. Wie auch die Ergebnisse eigener Untersuchungen zeigen, treten diese Arten jedoch nur dann auf, wenn ein Wald an die Feldflur angrenzt (z.B. an den Standorten $\mathrm{Bra}$, Hal1, Hal2 und Hal6). Die Arten breiten sich also nicht über große Entfernungen hinweg in alle Ackerbiotope aus. LUCZAK (1979) schreibt, daß die Waldarten häufiger die Ränder der Felder besiedeln als deren Zentrum. Das Auftreten von Waldarten in den Äckern ist daher weniger auf eine Anpassung dieser Arten an die Besonderheiten der Kulturbiotope zu verstehen, sondern auf das Phänomen des Randeffektes (vgl. HEUBLEIN 
1983). Dafür sprechen auch die stets niedrigen Fangzahlen der Waldarten. Neben den oben aufgeführten, die auch in der Hecke vorkommen, nennt LUCZAK (1979) Tetragnatha pinicola, Mangora acalypha, Microlinyphia pusilla und Linyphia triangularis. Diese Arten werden auch von NYFFELER (1982) als charakteristisch für Äcker und Mähwiesen aufgeführt. Diese netzbauenden Spinnen sind in der Krautschicht lichter Wälderverbreitet und finden zwischen den Halm- und Blattstrukturen der Kulturpflanzen und Wildkräutern geeignete Anheftungspunkte für den Netzbau sowie für sie günstige mikroklimatische Verhältnisse vor. Sie fehlen deshalb weitgehend in bestimmten Anbaukulturen wie Kartoffeln, die davon abweichende abiotische und strukturelle Parameter besitzen.

Wo stammen jedoch diejenigen Arten her, die im gesamten Gebiet von Mitteleuropa in allen Kulturfeldtypen verbreitet sind und die zahlenmäßig den größten Anteil der Ackerzönosen bilden?

Ein Blick in die ersten beiden Artengruppen im vorangegangenen Unterkapitel zeigt, daß von 12 aufgeführten Arten acht zu den Linyphiiden gehören. In der Literatur werden die meisten von innen als extreme r-Strategen (LUCZAK 1979), aktive Fadenflieger (DUFFEY 1956) und eurytop (HÄNGGI et al. 1995) beschrieben. Sie treten in allen Freiflächenbiotopen (HÄNGGI et al. 1995) und selbst an Bäumen mitten in Wäldern (PLATEN 1992) mit z.T. hohen Individuenzahlen auf. Auf extrem gestörten und isolierten Standorten, wie z.B. innerstädtischen Ruderalflächen, Parks und Starßenstreifen sind sie z.T. die einzigen Vertreter der Spinnenfauna, die mit höheren Individuenzahlen vertreten sind (KEGEL \& PLATEN 1983, KÄSTNER 1995, PLATEN \& KOWARIK 1995). Das bedeutet, daß im Gegensatz zu den oben aufgeführten Arten, die in den Gruppen I und II genannten aufgrund ihrer nahezu vorhandenen Omnipräsenz und ihrer extremen ökologischen Plastizität in der Lage sind, einen Ackerstandort, egal mit welcher Feldfrucht, schnell und auf Dauer erfolgreich zu besiedeln. Als naturnahe Herkunftsbiotope dieser Arten können Freiflächen jeglicher Art angenommen werden, von denen her ständig Ausbreitungsflüge am Fadenfloß zu neu entstandenen Freiflächen unternommen wurden.

Zum Schluß der Diskussion soll noch eine immer wieder zitierte Aussage kritisch betrachtet werden. LUCZAK (1979), NYFFELER (1982) u. a. schreiben, daß Spinnen der Getreidefelder den Standort jedes Jahr von den Rändern her neu besiedeln. Die Frage dabei ist, aus welchen naturnahen Habitaten kommen sie? Nach der obigen Aussage sind sie zwar nahezu omnipräsent, jedoch ist in vielen Gegenden unsere Landschaft flächenmäßig mehr von Kulturfeldern als von naturnahen Habiaten geprägt.

BRISTOWE (1939) schätzt 2 Mio. Spinnen auf 1 ha Kulturland. Die Möglichkeit, diese enorme Zahl jedes Jahr sowohl aus nahen als auch aus 
fernen, meist flächenmäßig viel kleineren Biotopen nachzuliefern, ist extrem unwahrscheinlich. Darüber hinaus müssen diese Flächen ebenfalls genügend Nachkommen hervorbringen, um die Populationen aufrecht erhalten zu können. Da die beiden Arten Erigone atra und Erigone dentipalpis an den meisten Kulturstandorten einen Individuenanteil von ca. $50 \%$ besitzen, müßten daher allein 1 Mio. Individuen von diesen beiden Arten pro ha und Jahr nachwandern. Eine gewaltige Völkerwanderung!

Darüber hinaus sind die Lebenszyklen vieler der auf den Äckern lebenden Arten zweijährig (z.B. Dicymbium brevisetosum, Diplostyla concolor, Linyphia triangularis (im Norden des Verbreitungsgebietes), Microneta viaria, Pirata piraticus (mit Einschränkungen) undTetragnatha extensa). Ihre Eiablagezeit erstreckt sich bis zum August, dem Zeitpunkt der Ernte. Tiso vagans ist einjährig, Pachygnatha degeeri entwickelt sich äußerst schnell, Pardosa pullata ist ebenfalls zweijährig, Xysticus cristatus sogar dreijährig (ALBERT 1982, TOFT 1976, 1978, 1979).

Die zweijährigen Arten überwintern meist zweimal, einmal als Juvenile und ein zweites Mal als Adulti (ALBERT 1982). Wenn jedoch durch die Bodenbearbeitung in den Kulturfeldern ein Großteil der Ackerarten stürbe, hieße das, daß sich trotz Neubesiedelung von außen aufgrund des zweijährigen Entwicklungszyklus die Populationen dieser Ackerarten ständig ausdünnen würden und schließlich ausstürben. Die Entwicklung verläuft zwar zeitlich versetzt, so daß in jedem Jahr ein gewisser Anteil geschlechtsreifer Tiere vorhanden ist, die Populationsgröße kann jedoch von Jahr zu Jahr erheblich schwanken. Daher kann die jährliche Neubesiedelung der Kulturflächen von außen lediglich eine Nachlieferung für Populationsverluste darstellen, die größte Anzahl der Individuen muß im Acker ihren Lebenszyklus durchlaufen, die Bearbeitungsmaßnahmen überleben und auch im Acker überwintern.

\section{LITERATUR}

ALBERT, R. (1982): Untersuchungen zur Struktur und Dynamik von Spinnengesellschaften verschiedener Vegetationstypen im Hoch-Solling. Diss. Universität Freiburg, Hochschulsammlung Biologie, Bd. 16

ASHIKBAYEV, N.Z. (1973): The life forms of spiders (Araneae) inhabiting wheat fields in the Kustanay region. - Entomol. Rev. 52: 335-341

ASSMUTH,W., A.BUSCHINGER, J.M.FRANZ, K.GROH\& W.TANKE (1986): Nebenwirkungen von Pflanzenschutzmitteln auf die Agrozönose von Zuckerrübenfeldern. In: H.FEHRMANN et al. (Bearb.), Herbizide II, DFG-Forschungsbericht, VCH, Weinheim: 44-79

BALOGH, J. \& I.LOSKA (1956): Untersuchungen über die Zoozönose des Luzernenfeldes. - Acta zool. Acad. Scient. Hungaricae 2: 17-114 
BARBER, H.S. (1931): Traps for cave inhabiting insects. - J. Elisha Mitchell sci. Soc. 31: 43-50 BASEDOW, T. (1973): DerEinfluß epigäischer Raubarthropoden auf die Abundanz phytophager Insekten in der Agrarlandschaft. - Pedobiologia 13: 410-422

BASEDOW, T. \& H.MIELKE (1977): Aspekte der Parathion-Anwendung in Weizenfeldern. - Nachrichtenbl. Dtsch. Pflanzenschutzd. Braunschweig 29: 65-69

BASEDOW, T. \& H.RZEHAK (1988): Abundanz und Aktivitätsdichte epigäischer Raubarthropoden auf Ackerflächen - ein Vergleich. - Zool. Jb. Syst. 115: 495-508

BASEDOW, T., A.BORG \& F.SCHERNEY (1976): Auswirkungen von Insektizidbehandlungen auf die epigäischen Raubarthropoden in Getreidefeldern, insbesondere die Laufkäfer (Coleoptera, Carabidae). - Ent. Exp. and Appl. 19: 37-51

BERLINER LANDESARBEITSGEMEINSCHAFT NATURSCHUTZ (BLN) (1982): Rettet Berlins Felder. - Broschüre der BLN, Berlin, $28 \mathrm{~S}$.

BEYER, R. (1978): Zur Spinnen- und Weberknechtfauna einer Kulturwiese in der Leipziger Tieflandsbucht. - Abh. Ber. Naturkundl. Museum,Mauritianum“ Altenburg 10: 181-198

BEYER, R. (1979): Zur Spinnen- und Weberknechtfauna einer Obstplantage mit Bedeckungsvarianten in der Umgebung von Leipzig. - Abh. Ber. Naturkundl. Museum „Mauritianum“ Altenburg 10:305-312

BEYER, R. (1981): Zur Dynamik der Spinnen-und Weberknechtfauna auf einer Kulturfläche mit wechselndem Pflanzenbestand im Verlauf von5 Jahren im Raum Leipzig. - Faun. Abh. Mus. Tierk. Dresden 8: 119-130

BLICK, T. (1988): Ökologisch-faunistische Untersuchungen an der epigäischen Spinnenfauna (Araneae) Oberfränkischer Hecken. Diplomarbeit, Universität Bayreuth, 104 S. \& Anhang

BLUME, H.-P. (Hrg.) (1981): Typische Böden Berlins. Exkursionsführer zur Jahrestagung 1981 der Deutschen Bodenkundlichen Gesellschaft. - Mitt. Dtsch. Bodenkundl. Ges. 31: 1-352

BONESS, M. (1953): Die Fauna der Wiesen unter besonderer Berücksichtigung der Mahd. - Z. Morph. Ökol. Tiere 42: 225-277

BONESS, M. (1958): Biozönotische Untersuchungen über die Tierwelt von Klee- und Luzernefeldern. - Z. Morph. Ökol. Tiere 47: 309-373

BRAUN, R. (1969): Zur Autökologie und Phänologie der Spinnen (Araneida) des NSG „Mainzer Sand" gleichzeitig ein Beitrag zur Kenntnis der Thermophilie bei Spinnen. - Mz. Naturw. Arch. 8: 193-288

BREYMEYER, A. (1978): Analyses of trophic structure of some grassland ecosystems. - Pol. ecol. Stud. 4: 55-128

BRISTOWE, W.S. (1939): The comity of Spiders Vol I. Ray Society, London

BROEN, B. v. (1985): Zur Kenntnis der Spinnenfauna des Berliner Raums. II. Spinnen eines isolierten Flurgehölzes. - Dtsch. ent. Z., (N.F.) 32: 239-250

BRUHN, K. (1990): Einfluß unterschiedlicher Bewirtschaftung von Winterroggenfeldern (konventionell und organisch-biologisch) auf die epigäische Spinnenfauna (Araneae). Diplomarbeit Freie Universität Berlin, $93 \mathrm{~S}$.

BÜCHS, W. (1993): Auswirkungen unterschiedlicher Bewirtschaftungsintensitäten auf die Arthropodenfauna von Winterweizenfeldern. - Verh. Ges. Ökologie 22:27-34

CLERCQ, R. de (1979): On the influence of the soil fauna on the aphid population in winter weat. - Int. Symp. "Integrated Control in Agriculture and Forestry" Wien: 79

COTTENIE, P. \& R. de CLERCQ (1977): Studie van de Arachnofauna in wintertarwevelden. - Parasitica 33: 138-147

CZAJKA, M. \& L.KANIA (1976): Spiders (Aranei) in potato agrocoenosis in Pawlowice Wielke near Worclaw in 1971-1974. - Pol. Pismo Ent. 46: 623-629 
DUFFEY, E. (1956): Aireal dispersion in a known spider population. - J. Anim. Ecol. 25: 571-599 HÄNGGI, A., E.STÖCKLI \& W.NENTWIG (1995): Lebenräume mitteleuropäischer Spinnen. - Miscellanea Faunistica Helvetiae. Centre suisse de cartographie de la faune (CSCF), Neuchâtel, $460 \mathrm{~S}$.

HEUBLEIN, D. (1983): Räumliche Verteilung, Biotoppräferenzenund kleinräumige Wanderungen der epigäischen Spinnenfauna eines Wald-Wiesen-Ökotons; ein Beitrag zum Thema "Randeffekt". - Zool. Jb. Syst. 110: 473-519

HEYDEMANN, B. (1953): Agrarökologische Problematik, dargetan an Untersuchungen über die Tierwelt der Bodenoberfläche der Kulturfelder. Diss., Univ. Kiel, $433 \mathrm{~S}$.

HUHTA, V. \& M.RAATIKAINEN (1974): Spider communities of leys and winter cereal fields in Finland. - Ann. Zool. Fenn. 11: 97-104

INGRISCH, S., U.WASNER \& E.GLÜCK (1989): Vergleichende Untersuchung der Ackerfauna auf alternativ und konventionell bewirtschafteten Flächen. In: W.KÖNIG, R.SUNKEL, U.NECKER, R.WOLFF-STRAUB, S.INGRISCH, U.WASNER\&E.GLÜCK(Hrsg.): Alternativerund konventionellerLandbau. -Schriftenreihe derLandesanstalt fürÖkologie, Landschaftsentwicklung und Forstplanung Nordrhein-Westfalen 11:113-282

JANUSCH, G. (1988): Zum Einfluß konventioneller, biologisch-organischer sowie biologischdynamischer Düngung von Äckern auf Spinnentiere (Araneae, Opiliones). Diplomarbeit, Freie Universität Berlin, $73 \mathrm{~S}$.

JONGMAN, R.H.G., C.J.F. ter BRAAK \& O.F.R.TONGEREN (Eds.) (1987): Data analysis in community and landscape ecology. Pudoc Books, Wageningen

KÄSTNER, S. (1995): Der Einfluß von Flächengestaltung und Pflege auf die Spinnen- und Weberknechtfauna (Araneida et Opilionida) innerstädtischer Straßenrandstreifen. Diplomarbeit, Freie Universität Berlin, $125 \mathrm{~S}$.

KAJAK, A. (1980): Do the changes caused in spider communities by the application of fertilizers advance with time? - Proc. Int. Arachnol. Congr., 8 th, Vienna: 115-119

KEGEL, B. \& R.PLATEN (1983): Faunistisch-ökologisches Gutachten ausgewählter Standorte von Berliner Straßen und Hinterhöfen, Teil: Carabidae - Laufkäferund Araneae-Webspinnen. Gutachten im Auftrage des Senators für Stadtentwicklung und Umweltschutz, unveröff. Mauskript, Berlin, $86 \mathrm{~S}$.

KEGEL, B. (1991): Freiland- und Laboruntersuchungen zur Wirkung von Herbiziden auf epigäische Raubarthropoden, insbesondere der Laufkäfer (Col.: Carabidae). Diss. Technische Universität Berlin, $237 \mathrm{~S}$.

KLEINHENZ, A.\&W.BÜCHS (1993): Einfluß verschiedenerlandwirtschaftlicher Produktionsintensitäten auf die Spinnenfauna in der Kultur Zuckerrübe. - Verh. Ges. Ökologie 22: 81-88

KORNECK, D. \& H.SUKOPP (1988): Rote Liste der in der Bundesrepublik ausgestorbenen, verschollenen und gefährdeten Farn- und Blütenpflanzen und ihre Auswertung für den Arten- und Biotopschutz. - Schr. R. Vegetationskde. 19: 1-210

KRAUSE, A. (1987): Untersuchungen zur Rolle von Spinnen in Agrarbiotopen. Diss., Univ. Bonn, $306 \mathrm{~S}$.

LUCZAK, J. (1975): Spider communities of crop-fields. - Pol. Ecol. Stud. 1: 93-110

LUCZAK, J. (1979): Spiders in agrocoenosis. - Pol. Ecol. Stud. 5: 151-200

LYS, J.-A. \& W.NENTWIG (1992): Augmentation of beneficial arthropods by strip-management. 4. Surface activity, movements and activity density of abundant carabid beetles in a cereal field. - Oecologia 92: 373-382

NÄHRIG, D. (1987): Spinnenfauna der oberen Strauchschicht von Hecken in Flurbereinigungsgebieten. Diss., Univ. Heidelberg, $250 \mathrm{~S}$. 
NYFFELER, M. (1982): Field studies on the ecological role of the spiders as insect predators in agroecosystems. (Abandonned grassland, meadows and cereal fields). Diss, ETHZürich, 174 S.

NYFFELER, M. \& G.BENZ(1981): Ökologische Bedeutung der Spinnen als Insektenprädatoren in Wiesen und Getreidefeldern. - Mitt. dtsch. Ges. allg. angew. Ent. 3: 33-35

PEUS, F. (1950): Die ökologische Determination des Hochmoores als „Steppe". - Veröff. Naturw. Ver. Osnabrück 25: 39-57

PLATEN, R. (1989): Struktur der Spinnen- und Laufkäferfauna (Arach.: Araneida, Col.: Carabidae) anthropogen beeinflußter Moorstandorte in Berlin (West); Taxonomische, räumliche und zeitliche Aspekte. Diss. Technische Universität Berlin, $470 \mathrm{~S}$.

PLATEN, R. (1992): Struktur und Dynamik der Spinnengemeinschaften im Staatswald Burgholz. - Jber. naturwiss. Ver. Wuppertal 45: 56-82

PLATEN, R.\&I.KOWARIK(1995): Dynamikvon Pflanzen-, Spinnen-und Laufkäfergemeinschaften bei der Sukzession von Trockenrasen zu Gehölzgesellschaften auf innerstädtischen Bahnbrachen in Berlin. - Verh. Ges. Ökologie 24: 431-439

PLATEN, R., M.MORITZ\& B.v.BROEN (1991): Liste derWebspinnen- und Weberknechtarten (Arach.: Araneida, Opilionida) des Berliner Raumes und ihre Auswertung für Naturschutzzwecke (Rote Liste). In: A.AUHAGEN, R.PLATEN \& H.SUKOPP (Hrsg.): Rote Listen der gefährdeten Pflanzen und Tiere in Berlin. - Landschaftsentw. Umweltforsch. S6: 169-205

PLATEN, R., T.BLICK, P.BLISS, R.DROGLA, A.MALTEN, J.MARTENS, P.SACHER \& J.WUNDERLICH(1995):Verzeichnis der Spinnentiere (excl. Acari) Deutschlands (Arachnida: Araneida, Opilionida, Pseudoscorpionida). - Arachnol. Mitt. S1: 1-55

RAATIKAINEN, M. \& V.HUHTA (1968): On the spider fauna of Finnish oat fields. - Ann. zool. Fenn. 5:254-261

RABELER, W. (1952): Die Tiergesellschaft hannoverscher Talfettwiesen (Arrhenatheretum elatoris). - Mitt. Flor. Soz. Arbeitsgem. (N. F.) 3: 130-140

RENKONEN, O. (1938): Statistisch-ökologische Untersuchungen über die Käferwelt der finnischen Bruchmoore. - Ann. Zool. Soc. Vanamo 6: 1-231

ROTTER, M. \& G.KNEITZ(1977): Die Fauna der Hecken und Feldgehölze und ihre Beziehung zur umgebenden Agrarlandschaft. - Waldhygiene 12: 1-82

RUZICKA, V. (1987): Biodiagnostic evaluation of epigeic spider communities. - Ekologia (CSSR) 6:345-357

SCHLICHTING, E., H.-P.BLUME \& K.STAHR (1995): Bodenkundliches Praktikum. Pareys Studientexte 81, Blackwall Wissenschafts-Verlag, Berlin, 2. A., 295 S.

SUKOPP, H. (Hrg.) (1990): Stadtökologie. D. Reimer, Berlin, 455 S.

SZODRA, F. (1983): Vergleichende Untersuchung der Spinnenfauna Berliner Ackerflächen. Staatsexamensarbeit für das Amt des Lehrers. Technische Universität Berlin, $157 \mathrm{~S}$.

THALER, K. \&H. M.STEINER(1975): Winteraktive Spinnen auf einem Acker bei Großenzersdorf (Niederösterreich). - Anz. Schädlingskde., Pflanzenschutz, Umweltschutz 48: 184-187

THALER, K., J.AUSSERLECHNER \& F.MUNGAST (1977): Vergleichende Fallenfänge von Spinnen und Käfern auf Acker- und Grünlandparzellen bei Innsbruck, Österreich. -Pedobiologia 17:389-399

TISCHLER, W. (1958): Synökologische Untersuchungen an der Fauna der Felder und Feldgehölze. - Z. Morph. Ökol. Tiere 47: 54-114

TISCHLER, W. (1965): Agrarökologie. G. Fischer, Jena, 499 S.

TISCHLER, W. (1980): Biologie der Kulturlandschaft, G. Fischer, Stuttgart,

TOFT, S. (1976): Life-histories of spiders in a Danish Beech Wood. - Nat. Jutl. 19: 5-40 
TOFT, S. (1978): Phenology of some Danish Beech-wood spiders. - Nat. Jutl. 20: 285-304

TOFT, S. (1979): Life histories of eight Danish wetland spiders. - Ent. Meddr. 47: 22-32

TRETZEL, E. (1952): Zur Ökologie der Spinnen (Araneae): Sber. physik. med. Soz. Erlangen 75:36-129

TURLEY, F. (1985): Untersuchungen über die Wirkung von Insektiziden auf die epigäische Spinnenfauna im Getreide. Diplomarbeit, Johann Wolfgang v.Goethe Universität, Frankfurt, $75 \mathrm{~S}$.

VICKERMAN, G. P. \& K.D.SUNDERLAND (1975): Arthropods in cereal crops: Nocturnal activity, vertical distribution and aphid predation. - J. appl. Ecol. 12: 755-766

ZWÖLFER, H. (1981): Hecken als ökologische Systeme. - Mitt. dtsch. Ges. allg. angew. Ent. 3: $9-11$

Dr. Ralph PLATEN, Institutfür Bodenzoologie und Ökologie, Freie Universität Berlin, Tietzenweg 85/87, D-12203 Berlin 